Key Words:

Characterization

RadBall $^{\mathrm{TM}}$

${ }^{137} \mathrm{Cs}$

WESF

Retention:

Permanent

\title{
Characterizing DOE Hanford Site Waste Encapsulation Storage Facility Cells Using RadBall $^{\mathrm{TM}}$
}

\author{
Co-Authors:
}

Eduardo B. Farfán

J. Rusty Coleman

Collaborators:

Steven Stanley

John Adamovics

Mark Oldham

Andrew Thomas

March 31, 2011

Savannah River National Laboratory

Savannah River Nuclear Solutions

Aiken, SC 29808 


\section{DISCLAIMER}

This work was prepared under an agreement with and funded by the U.S. Government. Neither the U. S. Government or its employees, nor any of its contractors, subcontractors or their employees, makes any express or implied:

1. warranty or assumes any legal liability for the accuracy, completeness, or for the use or results of such use of any information, product, or process disclosed; or

2. representation that such use or results of such use would not infringe privately owned rights; or

3. endorsement or recommendation of any specifically identified commercial product, process, or service.

Any views and opinions of authors expressed in this work do not necessarily state or reflect those of the United States Government, or its contractors, or subcontractors.

Printed in the United States of America

Prepared for

U.S. Department of Energy 
Key Words:

Characterization

RadBall $^{\mathrm{TM}}$

${ }^{137} \mathrm{Cs}$

WESF

Retention:

Permanent

\title{
Characterizing DOE Hanford Site Waste Encapsulation Storage Facility Cells Using RadBall $^{\mathrm{TM}}$
}

\author{
Co-Authors:
}

Eduardo B. Farfán

J. Rusty Coleman

Collaborators:

Steven Stanley

John Adamovics

Mark Oldham

Andrew Thomas

March 31, 2011

Savannah River National Laboratory

Savannah River Nuclear Solutions

Savannah River Site

Aiken, SC 29808 


\section{REVIEWS AND APPROVALS}

Signature on File

$03 / 31 / 2011$

Eduardo B. Farfán, Co-author, Environmental Science \& Biotechnology

Date

Signature on File

$03 / 31 / 2011$

J. Rusty Coleman, Co-author, Applied Comp. Eng. \& Statistics

Date

Signature on File

$03 / 31 / 2011$

G. Timothy Jannik, Peer Reviewer, Environmental Science \& Biotechnology

Date 


\section{TABLE OF CONTENTS}

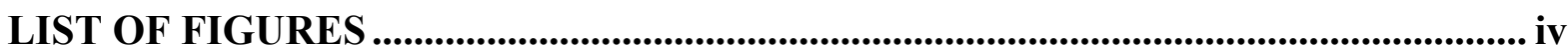

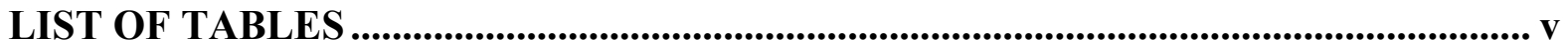

LIST OF ACRONYMS ............................................................................................................ vi

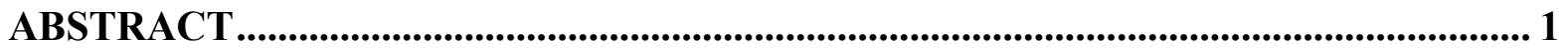

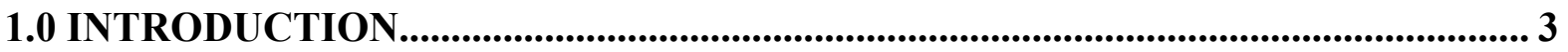

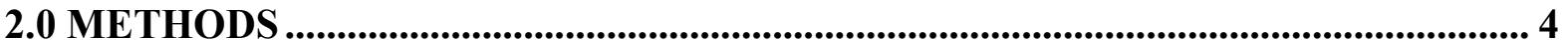

3.0 RESULTS AND DISCUSSION ................................................................................... 15

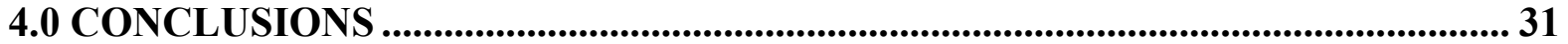

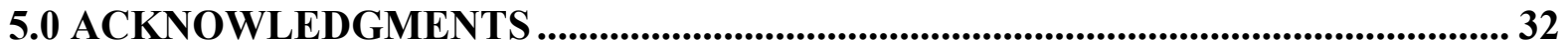

6.0 DISCLAIMER_................................................................................................................... 32

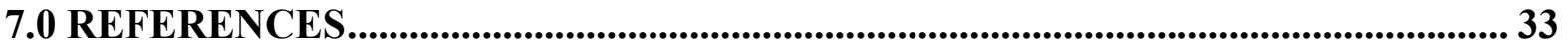




\section{LIST OF FIGURES}

Figure 1 - Two components of a RadBall ${ }^{\mathrm{TM}}$ device: the outer tungsten collimator with $\operatorname{RDDS}^{\mathrm{TM}}$ and inner radiosensitive PRESAGE ${ }^{\mathrm{TM}}$ polymer core........................... 5

Figure 2 - Schematic representation of the optical computed-tomography scanner developed by Duke University Medical Center. ................................................................. 5

Figure 3 - Hanford Site Waste Encapsulation and Storage Facility Capsule [SRNL representation based on Knight's image (1974)]............................................. 6

Figure 4 - The six-step process to characterize radiation sources within a contaminated area using RadBall ${ }^{\mathrm{TM}}$......

Figure 5 - Preparation for a RadBall ${ }^{\mathrm{TM}}$ deployment at WESF. A) RadBall ${ }^{\mathrm{TM}}$ containing $^{\mathrm{T}}$ PRESAGE $^{\mathrm{TM}}$ polymer. B) Triple-bagged RadBall ${ }^{\mathrm{TM}}$. C) Placing RadBall ${ }^{\mathrm{TM}}$ inside an airtight container. D) Complete RadBall ${ }^{\mathrm{TM}}$ device for a submerged

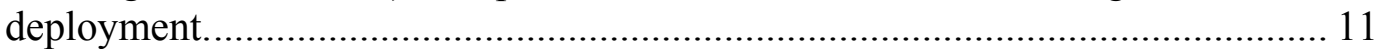

Figure 6 - A) RadBall ${ }^{\mathrm{TM}}$ deployment into WESF Cell 7. B) Submerged RadBall ${ }^{\mathrm{TM}}$. C) Directionality indicated by the black arrow on the airtight RadBall ${ }^{\mathrm{TM}}$ container. 12

Figure 7 - Representation of the N-52-3 and N-52-4 RadBall ${ }^{\mathrm{TM}}$ deployments in Cell 6...... 15

Figure 8 - The (A) pre-irradiated and (B) over-irradiated (N-52-2) PRESAGE ${ }^{\mathrm{TM}}$ polymer. . 17

Figure 9 - Representation of the RadBall ${ }^{\mathrm{TM}}$ characterization capabilities in water given by the spherical volume. The different colors of the four concentric cones represent various intensities identified by $\mathrm{RadBall}^{\mathrm{TM}}$ (e.g., white represents the highest intensity, red: second highest, etc.)................................................................ 19

Figure 10 - 2D ImageJ images of the irradiated PRESAGE ${ }^{\mathrm{TM}}$ polymers at WESF............... 20

Figure 11 - RadBall ${ }^{\mathrm{TM}}$ Characterization of Cell 6 (N-52-3): Side view, facing south. .......... 21 Figure 12 - RadBall ${ }^{\mathrm{TM}}$ Characterization of Cell 6 (N-52-3). A) View down looking west. B)

Top view facing south......................................................................... 22

Figure 13 - Cherenkov radiation glow: A) Cell 6. B) Cell 7 ............................................. 23

Figure 14 - Overlay of RadBall ${ }^{\mathrm{TM}}$ Characterization of Cell 6 (N-52-3) and Cherenkov radiation glow. A) Top view facing south. B) Side view facing south................ 24

Figure 15 - RadBall ${ }^{\mathrm{TM}}$ Characterization of Cell 6 (N-52-4): Side view, facing south. .......... 25

Figure 16 - RadBall ${ }^{\mathrm{TM}}$ Characterization of Cell 6 (N-52-4). A) View down looking west. B) Top view facing south......................................................................... 26

Figure 17 - Overlay of RadBall ${ }^{\mathrm{TM}}$ Characterization of Cell 6 (N-52-4) and Cherenkov radiation glow. A) Top view facing south. B) Side view facing south............... 27

Figure 18 - Combined results from both WESF Cell 6 characterizations (N-52-3 and N-52-4).

Figure 19 - N-52-1 RadBall ${ }^{\mathrm{TM}}$ characterization of WESF Cell 7: A) Side view facing south.

B) View down looking west. C) View down looking east. D) Top view facing

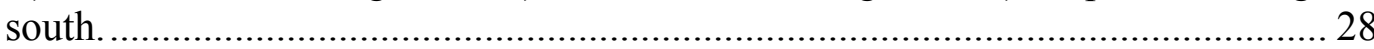

Figure 20 - The overlay images of the BRACE ${ }^{\mathrm{TM}}$ characterization and Cherenkov radiation:

A) Top view and B) side view of Cell 6, facing south. ................................. 29

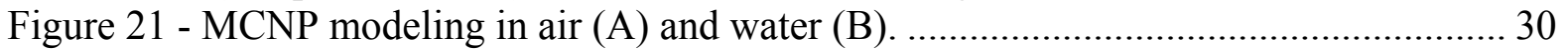




\section{LIST OF TABLES}

Table 1 - Hanford Site WESF ${ }^{137} \mathrm{CsCl}$ capsule loading and temperature ${ }^{\mathrm{a}}$ (Knights 1974),...... 7

Table 2 - Hanford Site WESF ${ }^{137} \mathrm{CsCl}$ capsule properties ${ }^{\mathrm{a}}$ (Knights 1974)........................... 7

Table 3 - RadBall deployments in Hanford Site WESF Cells 6 and 7 ................................. 16

Table 4 - Mass attenuation coefficient and photon mean free path in air and water.............. 17

Table 5 - Average number of photon interactions per distance in air and water.................... 18 


\section{LIST OF ACRONYMS}

BRACE SRNL's Back-projected Radiation Analyzer and Cell Evaluator

DOE United States Department of Energy

DMOS Duke Mid-sized Optical CT Scanner

CCD Charged Couple Device

NNL United Kingdom's National Nuclear Laboratory

OD Optical Density

ORNL Oak Ridge National Laboratory

RDDS Radially Dependant Directional Shield

RI Refractive Index

RTS NNL-developed RadBall ${ }^{\mathrm{TM}}$ Tool Software

SRNL Savannah River National Laboratory

SRNS Savannah River Nuclear Solutions

SRS

Savannah River Site

WESF United States Hanford Site's Waste Encapsulation Storage Facility 


\begin{abstract}
RadBall $^{\mathrm{TM}}$ is a novel technology that can locate and quantify unknown radioactive hazards within contaminated areas, hot cells, and gloveboxes. The device consists of a colander-like outer tungsten collimator that houses a radiation-sensitive polymer semi-sphere. The collimator has a number of small holes with tungsten inserts; as a result, specific areas of the polymer are exposed to radiation becoming increasingly more opaque in proportion to the absorbed dose. The polymer semi-sphere is imaged in an optical computed tomography scanner that produces a high resolution 3D map of optical attenuation coefficients. A subsequent analysis of the optical attenuation data using a reverse ray tracing or backprojection technique provides information on the spatial distribution of gamma-ray sources in a given area forming a $3 \mathrm{D}$ characterization of the area of interest. RadBall ${ }^{\mathrm{TM}}$ was originally designed for dry deployments and several tests, completed at Savannah River National Laboratory and Oak Ridge National Laboratory, substantiate its modeled capabilities. This study involves the investigation of the RadBall ${ }^{\mathrm{TM}}$ technology during four submerged deployments in two water filled cells at the DOE Hanford Site's Waste Encapsulation Storage Facility.
\end{abstract}


This Page Intentionally Left Blank 


\subsection{INTRODUCTION}

The consequences of radiological operations at various U.S. Department of Energy (DOE) sites have resulted in substantially contaminated facilities (e.g., reactors, fuel and isotope processing facilities, laboratories, hot cells, gloveboxes, etc.) and facilities housing highly radioactive materials (fuel storage facilities, underwater basins, etc). These facilities are usually associated with extremely high dose rates and, therefore, it is essential to use remote technologies for characterization and decommissioning to keep worker exposures as low as reasonably achievable in these highly radioactive environments. Although technologies might exist in other industry applications that could be tested, modified, and deployed for characterization and decommissioning efforts throughout the DOE complex, development of new and innovative technologies is also needed. In addition, even though it might be possible to complete these tasks without remote/robotic systems, the benefits of remote systems to safety/ALARA and cost/schedule are expected to be substantial. A critical initial step in planning and implementing decontamination and decommissioning of contaminated facilities involves the development of an accurate assessment of the radiological, chemical, and structural conditions inside of the facilities. These conditions are often unknown for many of these facilities. Radiological and chemical contamination, as well as structural deterioration of such facilities presents risks to workers, which must be mitigated. To the extent that information can be collected to describe facility conditions using remote technologies, the conservatism associated with planning initial worker entry (and associated cost) can be reduced. For facilities confirmed to be high hazard, remote and robotic technologies for characterization, decontamination and decommissioning can further reduce the costs to mitigate worker risks.

Various national and international organizations (e.g., the United States Department of Energy, Department of Defense, Department of Homeland Security, Nuclear Regulatory Commission, Environmental Protection Agency, and the International Atomic Energy Agency) deal with radioactive contamination on a regular basis. These organizations have expressed the need for better radiation detector systems to characterize and locate unidentified sources of radiation such as hot spots within glove boxes, hot cells, and other confined spaces where elevated radiation levels exist. These systems should provide 3D characterizations of the affected areas while having valuable properties that include low cost, robustness, and stability against falls, impacts, and extreme temperatures. In addition, the systems should be remotely deployable during the measurement/characterization process (no connecting power, communication cords or electronics) to ensure a high degree of deployability that may open up new possibilities for radiation measurement and mapping in areas of a facility, which were previously considered physically inaccessible with traditional electrical-based radiation detection systems. A suitable technology should also offer an inexpensive and safer means to perform initial radiological characterizations, in-process surveys, and final status surveys to enable effective decontamination while minimizing exposures to workers.

Savannah River National Laboratory (SRNL) addressed key aspects of the testing and further development of an innovative technology, RadBall ${ }^{\mathrm{TM}}$; originally developed by the National Nuclear Laboratory (NNL) in the United Kingdom (Stanley 2008; Stanley and Holmes 2010; 
Farfán et al. 2010a, 2010b, 2010c; Oldham et al. 2010; Farfán et al. 2011). The RadBall ${ }^{\mathrm{TM}}$ technology presents a significant opportunity to expedite initial characterization of radiologically contaminated facilities with respect to ALARA concerns, initial decontamination strategies, and costs associated with the decontamination efforts. RadBall ${ }^{\mathrm{TM}}$ will make radiation mapping safer and potentially more accurate and convenient than conventional detection devices, which are often much bigger and cumbersome due to their electrical components and accessories. A single RadBall ${ }^{\mathrm{TM}}$ can be positioned in a highly contaminated area, glove box, or hot cell and left alone to collect data instead of personnel spending valuable time carrying out manual scanning and surveying.

This study completed at the DOE Hanford Site's Waste Encapsulation Storage Facility (WESF) involved four RadBall ${ }^{\mathrm{TM}}$ deployments in WESF Cells 6 and 7. All the previous tests of the RadBall ${ }^{\mathrm{TM}}$ technology completed at the United Kingdom's National Nuclear Laboratory (NNL), Savannah River National Laboratory (SRNL) and Oak Ridge National Laboratory (ORNL) have included dry tests involving known and unknown radiation sources (e.g., hot cells, x-ray machines, sealed sources, etc.). This study is unique because it is the first time that a test involving submerged RadBall ${ }^{\mathrm{TM}}$ deployments has been investigated.

\subsection{METHODS}

The RadBall ${ }^{\mathrm{TM}}$ device consists of a colander-like outer tungsten shell that houses a radiationsensitive PRESAGE ${ }^{\mathrm{TM}}$ polymer semi-sphere (Figure 1) (Adamovics and Maryanski 2006; Doran et al. 2008; Guo et al. 2006a, 2006b, 2006c; Sakhalkar et al. 2009). The outer shell includes SRNL-designed tungsten inserts known as Radially Dependant Directional Shield $\left(\operatorname{RDDS}^{\mathrm{TM}}\right)$. The tungsten shell with the RDDS ${ }^{\mathrm{TM}}$ works to collimate radiation sources and those areas of the polymer semi-sphere that are exposed react, becoming increasingly less transparent, in proportion to the absorbed dose. The polymer semi-sphere is imaged in an optical-CT scanner developed at Duke University Medical Center (Figure 2) (Oldham 2006; Oldham et al. 2010), which produces a high resolution 3D map of optical attenuation coefficients. The orientation of the opacity track provides the positional information regarding the source, which is achieved by using a reverse ray tracing or back-projection technique. The activity of the detected source is assessed by quantifying the magnitude of the opacity change that follows a linear relationship with respect to absorbed dose. Radiation sources are characterized by studying the depth of the opacity track (the measured opacity in the track over the depth of the track will follow a function that can be interpreted to estimate the characteristic energy or energies of the incident radiation source).

\section{Hanford Site Waste Encapsulation and Storage Facility}

These experiments were completed at the Hanford Site Waste Encapsulation and Storage Facility (WESF), adjacent to the B Plant processing facility in the Hanford Site's 200-East Area. The objective of this study was to characterize WESF Cells 6 and 7. 


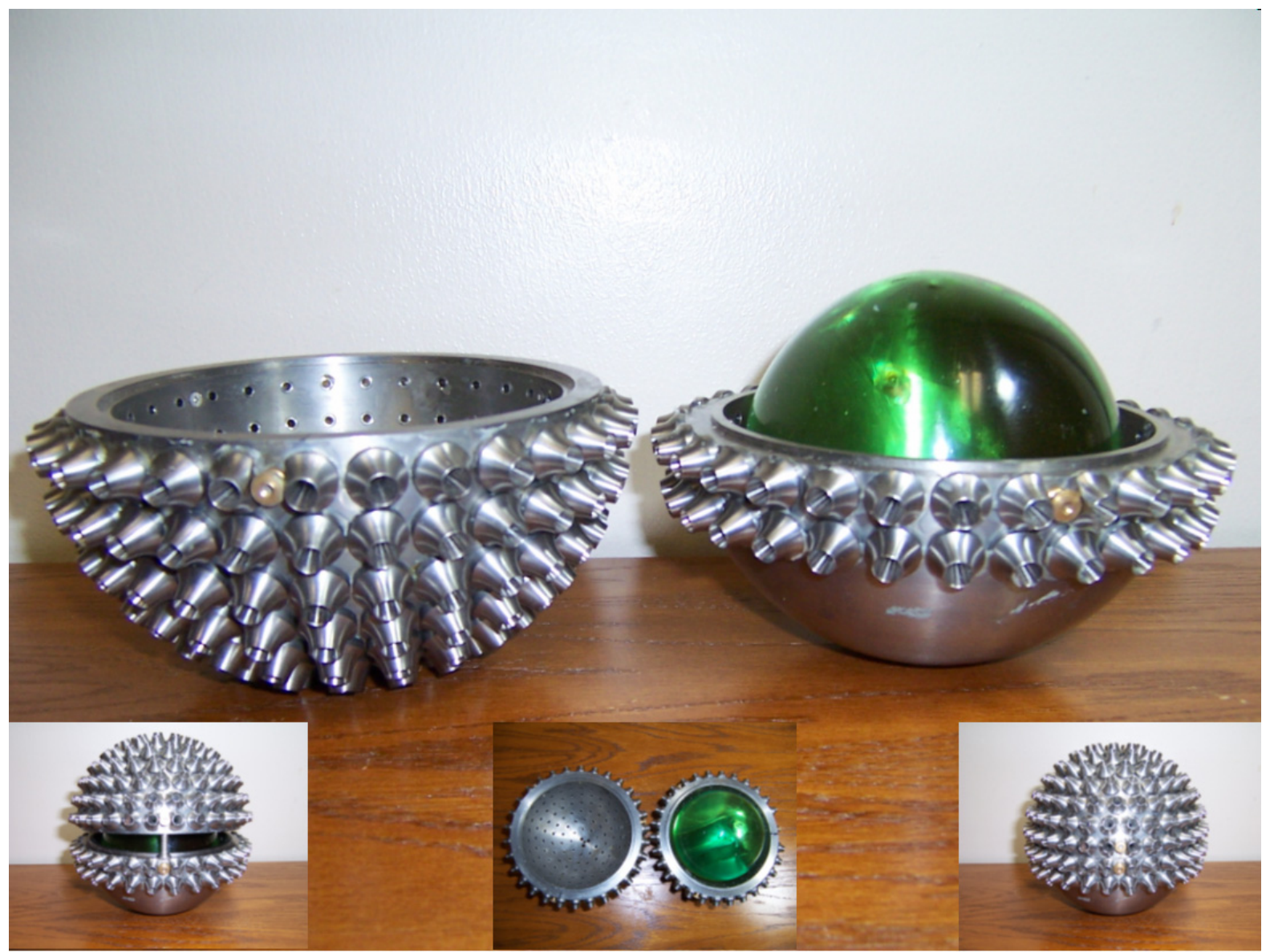

Figure 1 - Two components of a RadBall ${ }^{\mathrm{TM}}$ device: the outer tungsten collimator with $\operatorname{RDDS}^{\mathrm{TM}}$ and inner radiosensitive PRESAGE ${ }^{\mathrm{TM}}$ polymer core.

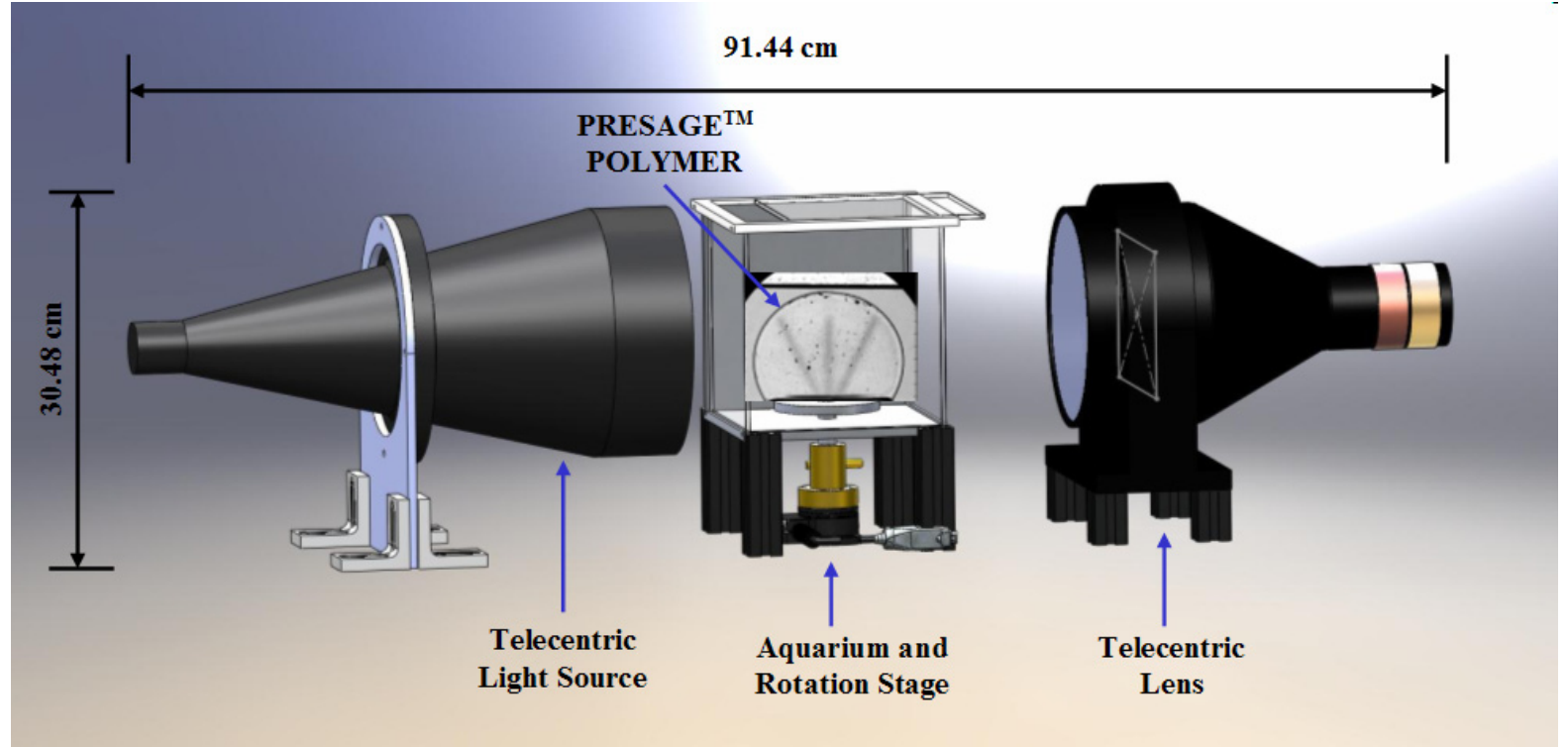

Figure 2 - Schematic representation of the optical computed-tomography scanner developed by Duke University Medical Center. 
In $1972,{ }^{137} \mathrm{Cs}$ and ${ }^{90} \mathrm{Sr}$ were removed from the high level waste tanks at the Hanford Site. These radionuclides, which generate a large amount of heat when they decay, had to be removed from single shell waste tanks to reduce the temperature of the waste inside these tanks. ${ }^{137} \mathrm{Cs}$ and ${ }^{90} \mathrm{Sr}$ were eventually placed in durable, stainless steel capsules; currently, located at WESF and stored as cesium chloride $\left({ }^{137} \mathrm{CsCl}\right)$ and strontium fluoride $\left({ }^{90} \mathrm{SrF}_{2}\right)$, respectively. There are 1,335 capsules of ${ }^{137} \mathrm{CsCl}$ and 601 capsules of ${ }^{90} \mathrm{SrF}_{2}$ stored in basins filled with water, which has a dual purpose: to protect workers from radiation and to maintain the capsules cool. The ${ }^{137} \mathrm{CsCl}$ and ${ }^{90} \mathrm{SrF}_{2}$ capsules will remain at WESF until they can be safely placed in a national repository (http://www.hanford.gov/page.cfm/WESF).

\section{${ }^{137} \mathrm{CsCl}$ characteristics and encapsulation}

${ }^{137} \mathrm{Cs}$ has a half-life of 30.17 years and its specific activity in the chlorine form is $25 \mathrm{Ci} \mathrm{g}^{-1}$. $25 \%$ of cesium produced in fission is ${ }^{137} \mathrm{Cs}$, which decays with the emission of beta particles and $0.662 \mathrm{MeV}$ gamma rays to stable barium. The beta particles produce the blue glow in water due to the Cherenkov radiation. The ${ }^{137} \mathrm{Cs}$ decay process generates radiation energy [at a rate of $0.13 \mathrm{~W} \mathrm{TBq}^{-1}\left(4.84 \mathrm{~kW} \mathrm{MCi}^{-1}\right)$ ], which is transformed into heat by the absorption of the emitted radiation within the source and source container (Knights 1974).

Double encapsulation has proven to be a highly reliable container of radioactive sources and involves the placing of one sealed capsule inside another. Figure 3 shows a WESF capsule (Knights 1974). The WESF ${ }^{137} \mathrm{CsCl}$ capsule properties, loading, and temperature are summarized in Table 1 and Table 2.

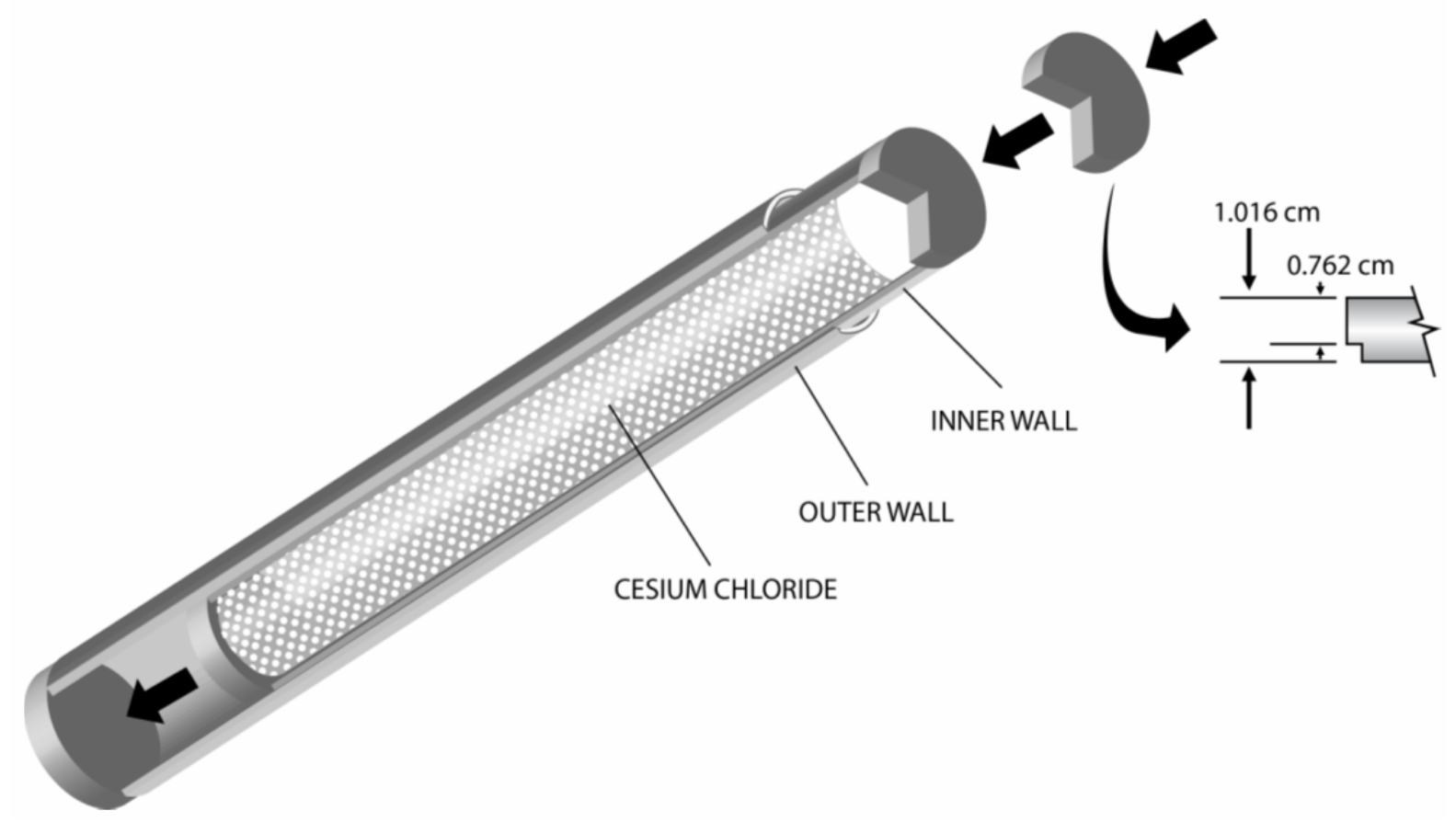

Figure 3 - Hanford Site Waste Encapsulation and Storage Facility Capsule [SRNL representation based on Knight's image (1974)]. 
The capsule centerline temperature in air and water were $450^{\circ} \mathrm{C}$ and $327^{\circ} \mathrm{C}$ in 1972 , respectively (the original loading is presented without accounting for radioactive decay). Type 316L stainless steel has been demonstrated to be the most resistant to ${ }^{137} \mathrm{CsCl}$ corrosive effects. The capsule wall thickness and weld joints were specifically designed for strength and potential stresses. An inert gas, usually helium, is placed at one end of the capsule, which is subsequently tungsten-arc welded. An ultrasonic test is then performed on the capsule. The inner capsule is filled with ${ }^{137} \mathrm{CsCl}$, covered with the cap, and tungsten-arc welded. After checking for inert gas leak, excessive ${ }^{137} \mathrm{CsCl}$ contamination is removed by cleaning the outer surface of the inner capsule thoroughly. The clean capsule is then inserted into the outer one. The outer capsule cap is welded and an ultrasonic test is performed. The outer capsule is decontaminated and placed in a water-filled basin for storage (Knights 1974).

Table 1 - Hanford Site WESF ${ }^{137} \mathrm{CsCl}$ capsule loading and temperature ${ }^{\mathrm{a}}$ (Knights 1974).

\begin{tabular}{|c|c|c|c|c|c|c|}
\hline \multirow[t]{3}{*}{ Form } & \multirow[t]{3}{*}{ Loading } & \multirow{3}{*}{$\begin{array}{c}\text { Percent of } \\
\text { Theoretical } \\
\text { Density }^{b} \\
\end{array}$} & \multicolumn{4}{|c|}{ Temperature } \\
\hline & & & \multicolumn{2}{|l|}{ Air } & \multicolumn{2}{|c|}{ Water } \\
\hline & & & Center Line & Surface & Center Line & Surface \\
\hline $\begin{array}{l}\text { Melt- } \\
\text { cast }\end{array}$ & $\begin{array}{c}2590 \mathrm{TBq} \\
(70 \mathrm{kCi})\end{array}$ & 65 & $450^{\circ} \mathrm{C}$ & $200^{\circ} \mathrm{C}$ & $327^{\circ} \mathrm{C}$ & $58^{\circ} \mathrm{C}$ \\
\hline
\end{tabular}

Table 2 - Hanford Site WESF ${ }^{137} \mathrm{CsCl}$ capsule properties ${ }^{\mathrm{a}}$ (Knights 1974).

\begin{tabular}{lccccc}
\hline Capsule & Material $^{\mathbf{b}}$ & $\begin{array}{c}\text { Wall } \\
\text { Thickness }^{\mathbf{b}}\end{array}$ & $\begin{array}{c}\text { Outside } \\
\text { Diameter }\end{array}$ & $\begin{array}{c}\text { Total } \\
\text { Length }\end{array}$ & $\begin{array}{c}\text { Total Cap } \\
\text { Thickness }\end{array}$ \\
\hline Inner & 316L Stainless Steel & 0.24 & 5.72 & 50.10 & 1.02 \\
Outer & 316L Stainless Steel & 0.28 & 6.67 & 52.77 & - \\
\hline
\end{tabular}

${ }^{\mathrm{a}}$ All dimensions are in $\mathrm{cm}$.

${ }^{\mathrm{b}}$ Ultrasonically tested.

\section{RadBall $^{\mathrm{TM}}$ deployment and retrieval}

A complete RadBall ${ }^{\mathrm{TM}}$ deployment and retrieval process consists of six individual steps illustrated in Figure 4 (Stanley 2008; Stanley and Holmes 2010; Farfán et al. 2011). These steps were slightly modified to account for the submerged RadBall ${ }^{\mathrm{TM}}$ deployments at WESF. Step 1 involved triple bagging RadBall ${ }^{\mathrm{TM}}$ to prevent it from becoming contaminated, putting it inside an airtight container (Figure 5), and placing it into a submerged WESF Cell. Knowing the RadBall ${ }^{\mathrm{TM}}$ position and orientation ensures an accurate use of the backprojection technique implemented in the SRNL-developed software titled Back-Projected Radiation Analyzer and Cell Evaluator (BRACE $\left.{ }^{\mathrm{TM}}\right)$.

A RadBall ${ }^{\mathrm{TM}}$ deployment could be accomplished by using a crane, manipulator, trolley, or robot; however, the deployments at WESF were completed by lowering RadBall ${ }^{\mathrm{TM}}$ with two ropes as shown in Figure 6 (the first rope was used to hold the device and the second one was used as a safety measure in case the first rope broke). Step 2 included knowing the radiation 
dose rates at the RadBall ${ }^{\mathrm{TM}}$ location within the WESF cell. This helped determine the optimal deployment time, during which $\mathrm{RadBall}^{\mathrm{TM}}$ remained still. Step 3 involved the retrieval of the device from the WESF Cell, checking for contamination and debagging the device. Step 4 included the removal of the irradiated radiosensitive PRESAGE ${ }^{\mathrm{TM}}$ polymer from the RadBall ${ }^{\mathrm{TM}}$ collimator.

\section{STEP 1: Place RadBall ${ }^{\mathrm{TM}}$ into position}

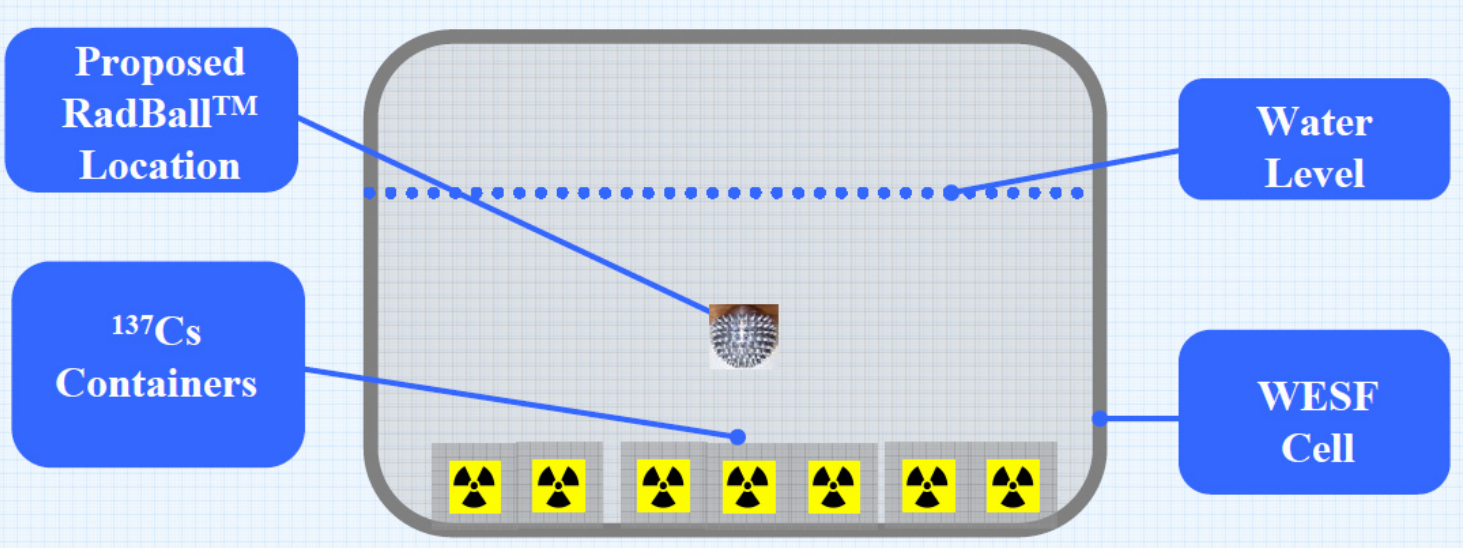

STEP 2: Leave RadBall ${ }^{\mathrm{TM}}$ for sufficient exposure time

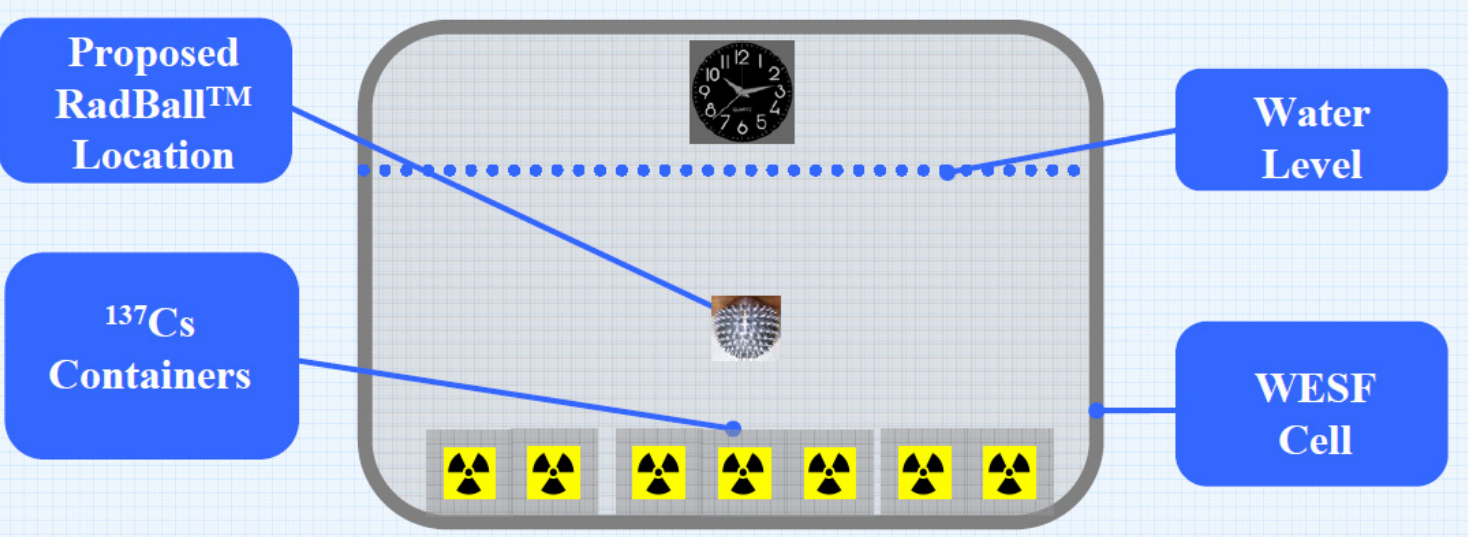

Figure 4 - The six-step process to characterize radiation sources within a contaminated area using RadBall ${ }^{\mathrm{TM}}$. 


\section{STEP 3: Remove RadBall ${ }^{\mathrm{TM}}$ from WESF Cell}

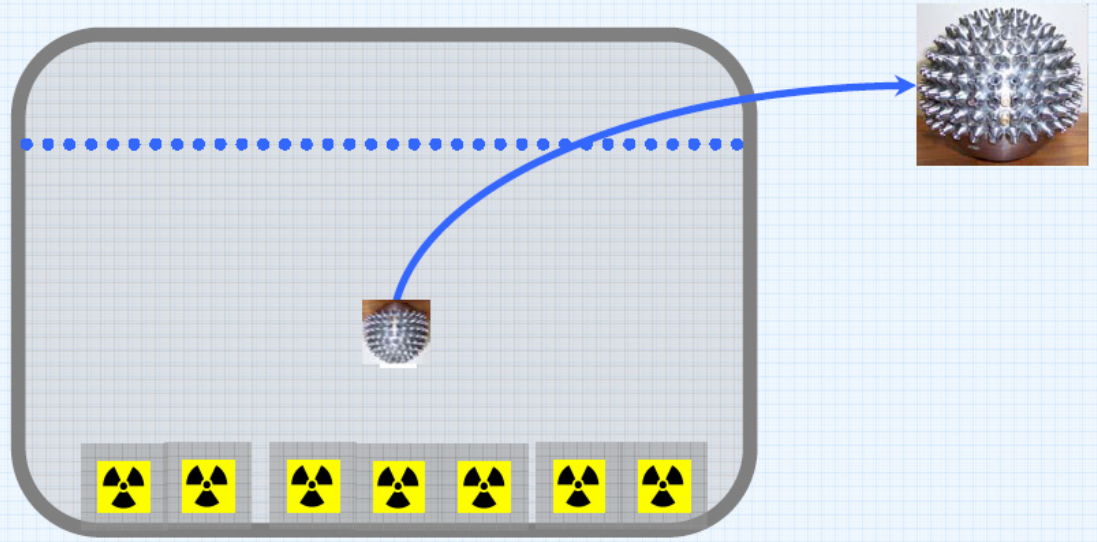

\section{STEP 4: Remove RadBall ${ }^{\mathrm{TM}}$ collimator}

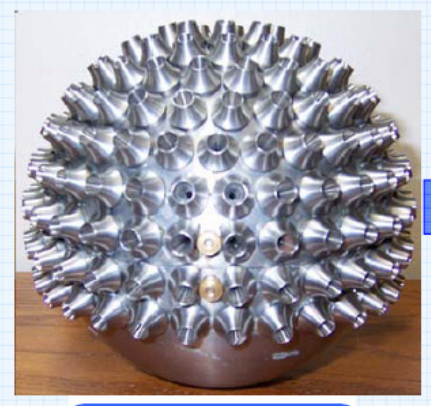

Complete

RadBall ${ }^{\mathrm{TM}}$

device

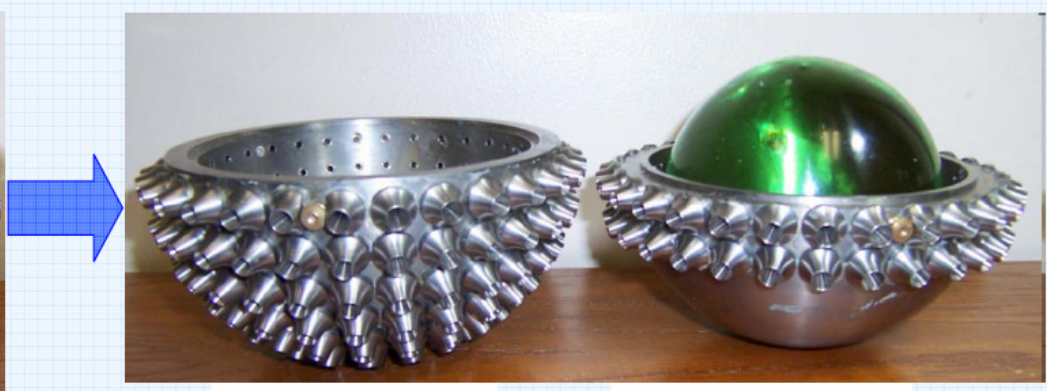

RadBall ${ }^{\mathrm{TM}}$ collimator

\section{PRESAGETM}

polymer

Figure 4 Cont. - The six-step process to characterize radiation sources within a contaminated area using RadBall ${ }^{\mathrm{TM}}$. 


\section{STEP 5: Analyze polymer using an optical CT scanner}

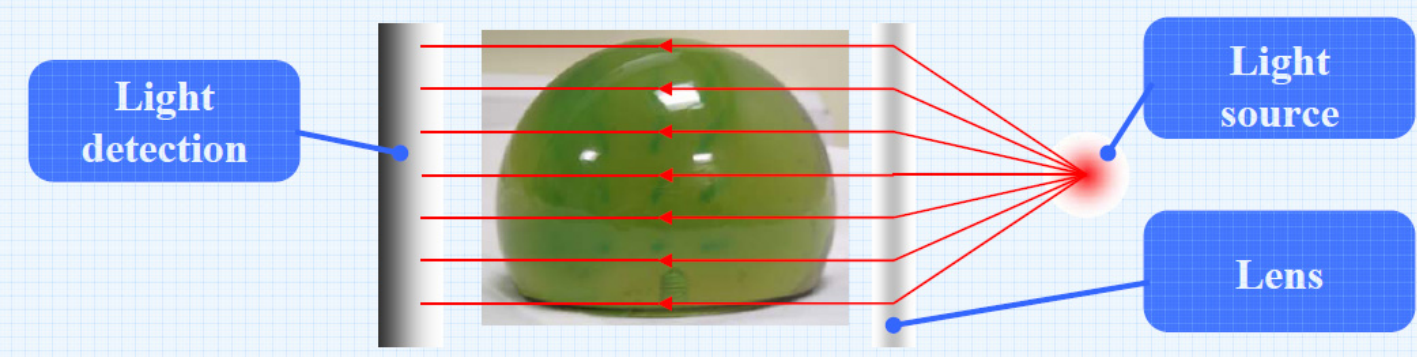

Polymer plastic sample is rotated $360^{\circ}$ to obtain $3 D$ information
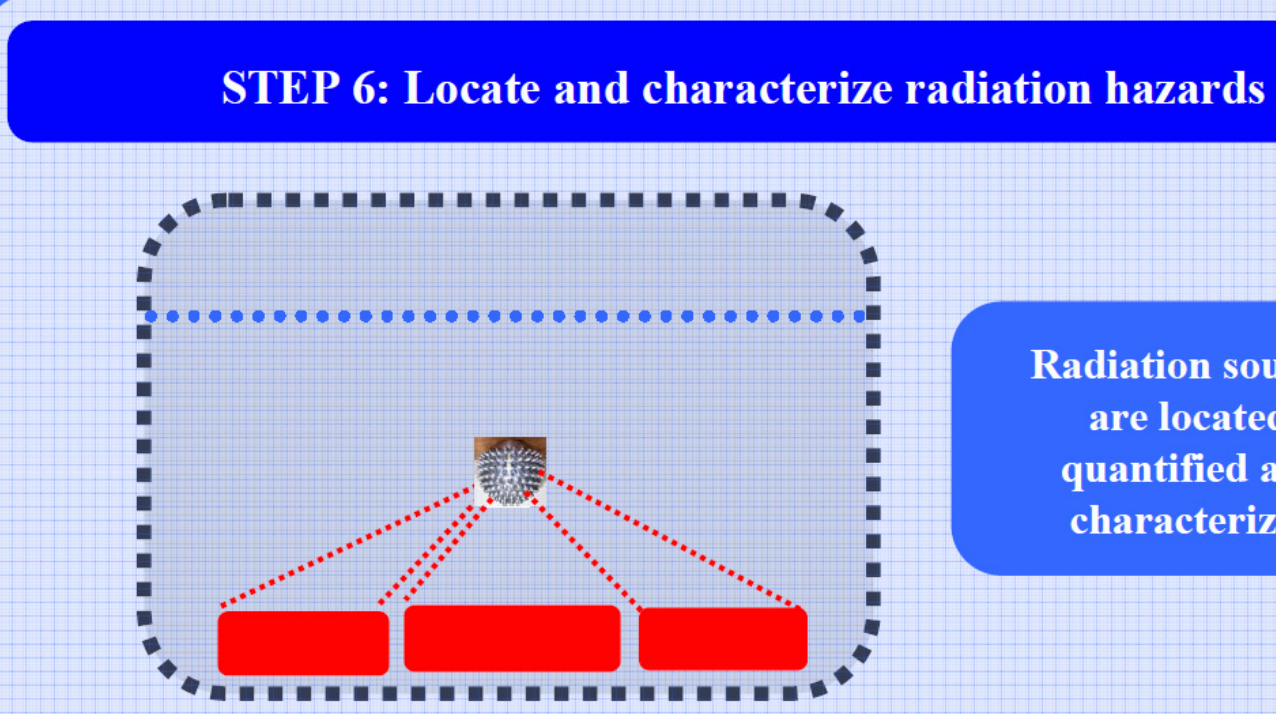

Radiation sources

are located, quantified and characterized

Figure 4 Cont. - The six-step process to characterize radiation sources within a contaminated area using RadBall ${ }^{\mathrm{TM}}$. 

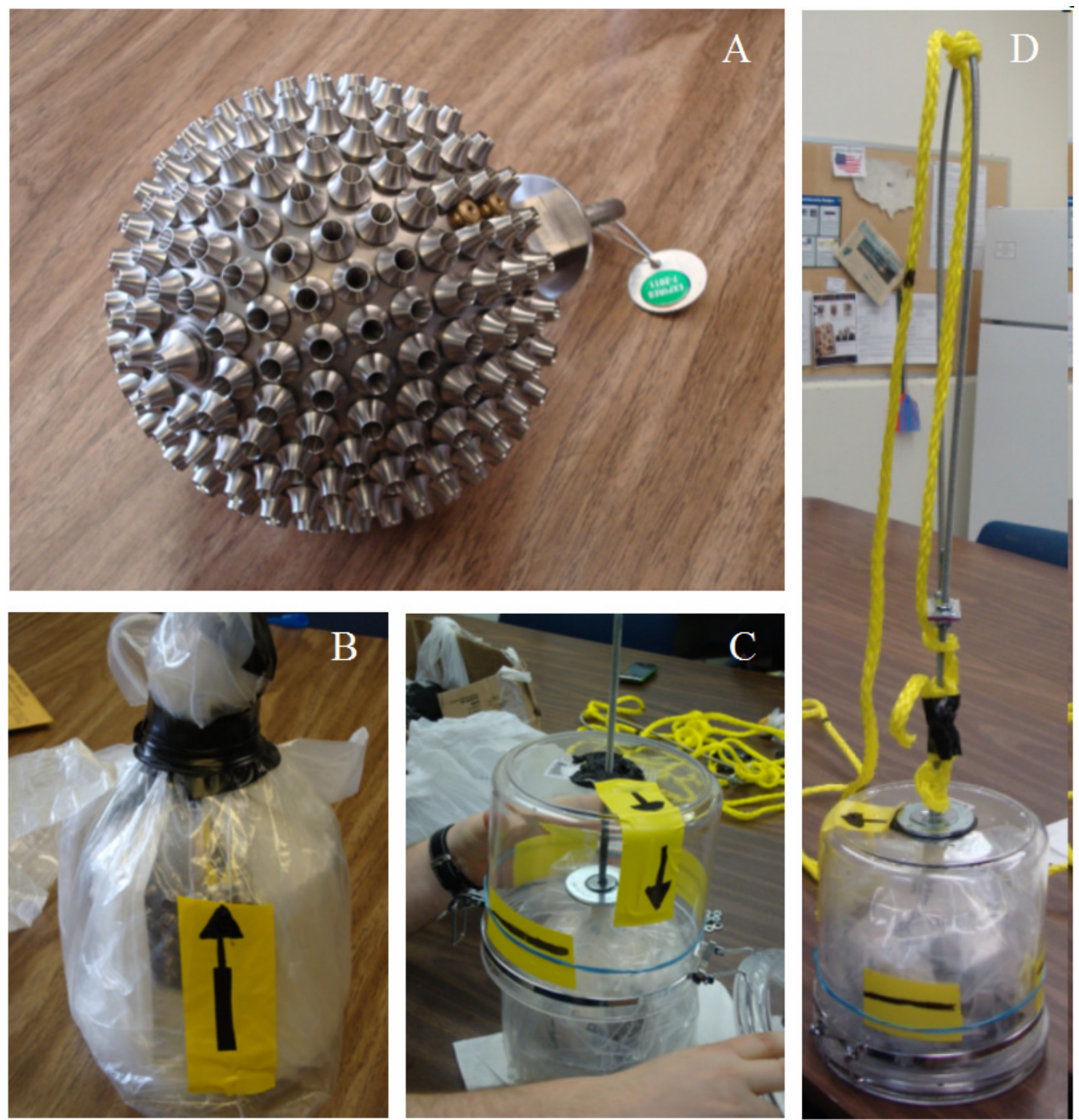
Figure 5 - Preparation for a RadBall ${ }^{\mathrm{TM}}$ deployment at WESF. A) RadBall ${ }^{\mathrm{TM}}$ containing
PRESAGE ${ }^{\mathrm{TM}}$ polymer. B) Triple-bagged RadBall ${ }^{\mathrm{TM}}$. C) Placing RadBall ${ }^{\mathrm{TM}}$ inside an airtight container. D) Complete RadBall ${ }^{\mathrm{TM}}$ device for a submerged deployment.

Step 5 involved the optical scanning of the polymer using the Duke Mid-sized Optical CT Scanner (DMOS). The scanning produced a matrix of values that indicate the change in optical density (OD) within the irradiated polymer. The OD change can be viewed using a personal computer (PC). DMOS consists of a telecentric light source, a charged couple device (CCD) camera with telecentric lens, a motor controlled rotation stage for rotating the polymer sample, an aquarium for holding the sample, an optical refractive index matching fluid and a PC with associated control and data acquisition software (Figure 2). The telecentric light source produces a parallel light beam that passes through the aquarium 
containing the irradiated polymer as well as a fluid with a refractive-index (RI) equivalent to that of the polymer. The resultant image is then collated using the telecentric lens and CCD camera. The aperture on the lens enables a variation in the acceptance angle of light rays that are allowed to form the image of $\sim 0.2-10^{\circ}$. Light rays that deviate from parallel with the optical axis by greater than the acceptance angle are excluded from the image. The system uses a commonly used Computed Tomography (CT) approach by taking a number of projections from different rotational positions of the polymer and using an image reconstruction algorithm to reconstruct a 3D 16-bit data cube representing the OD change distribution within the polymer. This data set can then be read using image manipulation software such as the Image Processing and Analysis in Java (ImageJ) software (website: http://rsbweb.nih.gov/ij/). The DMOS is able to show radiation tracks within the irradiated polymer when exposed to a least $0.01 \mathrm{~Gy}$. The system has a spatial resolution of about $2 \mathrm{~mm}$. The scanning and data analyses take approximately 30 minutes.

After the radiation sensitive polymer has been optically scanned, the data is interpreted in Step 6 to produce a final visualization that allows the determination of the source locations within the contaminated area. NNL and SRNL have independently developed two different methodologies to produce the final visualization. The two distinct approaches are described next.

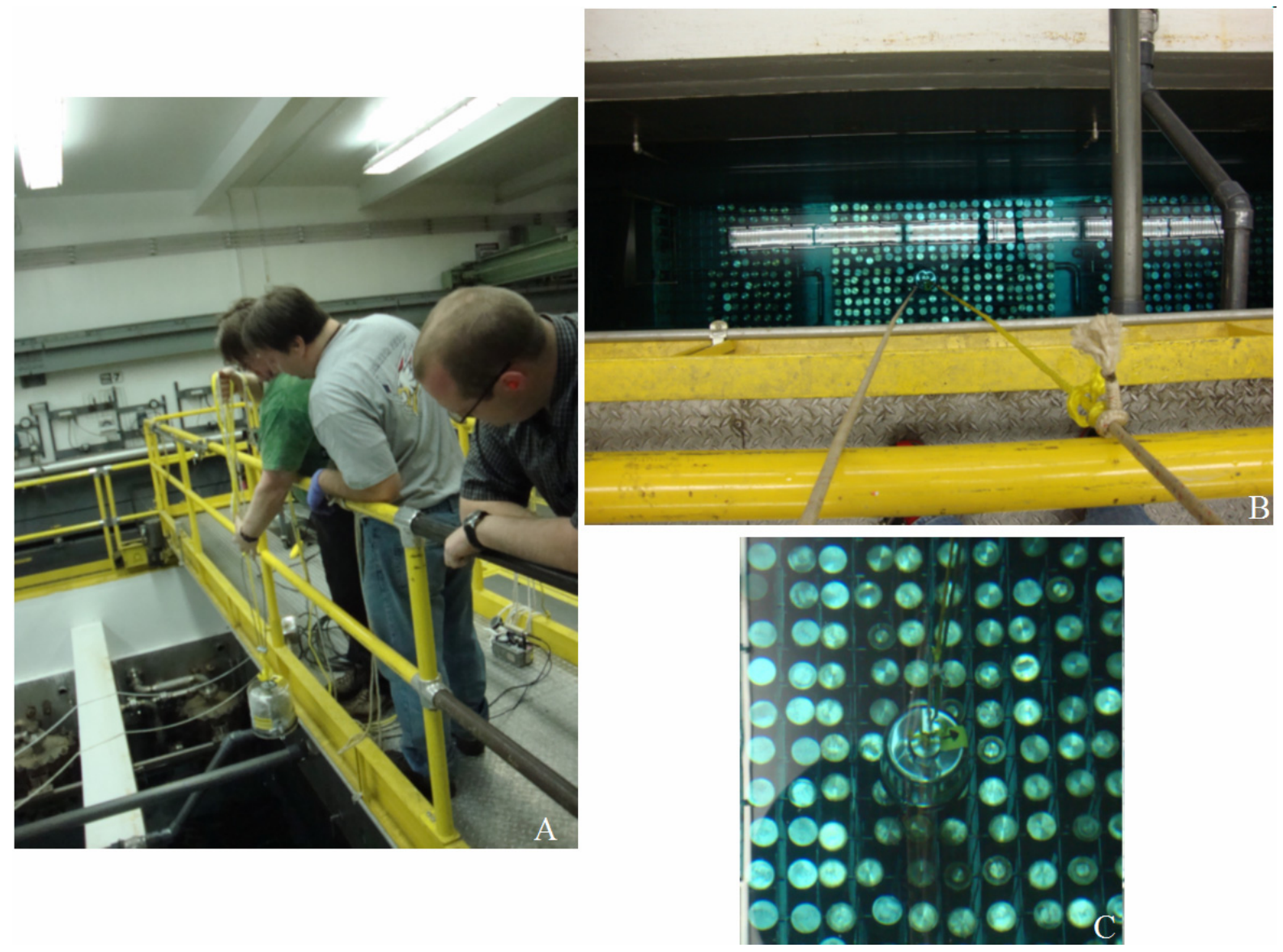

Figure 6 - A) RadBall ${ }^{\mathrm{TM}}$ deployment into WESF Cell 7. B) Submerged RadBall ${ }^{\mathrm{TM}}$. C) Directionality indicated by the black arrow on the airtight RadBall ${ }^{\mathrm{TM}}$ container. 


\section{NNL's reverse ray tracing technique}

A reverse ray tracing technique is applied to determine the location of radiation sources within a contaminated room. ImageJ is used for the direct visualization of the scan results in the form of a stack of $2 \mathrm{D}$ images. This stack of images can be scrolled through to give the effect of 'moving through' the radiation sensitive polymer. The scan file can be directly imported into ImageJ and properties such as the brightness and contrast are adjusted to make the tracks through the RadBall ${ }^{\mathrm{TM}}$ easier to identify. The data is in the form of a list of coordinates and corresponding intensities. These data lists, usually one per track, are then converted into a universal coordinate system for input into the next stage of the analysis in the NNL-developed RadBall ${ }^{\mathrm{TM}}$ Tool Software (RTS).

Once all data points have been converted to a universal coordinate system a data file is created in the correct format to be readable by RTS. This consists of several tabs, specifically named, which hold information such as the track data, the mark point, the vector the mark is orientated, the size and shape of the deployment volume and the location and orientation of the RadBall ${ }^{\mathrm{TM}}$ within the deployment volume. The first tab is used to view the deployment area and the location of the RadBall ${ }^{\mathrm{TM}}$ within the deployment area. The second tab is used to view the data points of all the tracks within the RadBall ${ }^{\mathrm{TM}}$.

For each track within the RadBall ${ }^{\mathrm{TM}}$, the RTS creates a line of best fit for the data points provided and chooses the direction of the track by using the intensity values. This line of best fit is extrapolated until it intersects with a wall of the deployment volume. This indicates that the radiation source is on the wall at this location or anywhere along the line of sight between the RadBall ${ }^{\mathrm{TM}}$ and the point on the wall. If two or more RadBall ${ }^{\mathrm{TM}}$ devices are deployed in different locations within the same deployment area, triangulation can be used to predict where along the extrapolated line the radiation source is. The third and final tab within the RTS is used to view the predicted radiation source locations. The RTS also has an image export function that exports each wall of the deployment area as a separate image. Each wall consists of a standard background color and areas of color change which represent locations of radiation sources. This area of color change is a Gaussian distribution about the extrapolated track intersection point on the wall. Higher intensity tracks within the RadBall $^{\mathrm{TM}}$ relate to brighter areas of color change. If more than one Gaussian overlaps, each has a weighted Gaussian calculated (by intensity) and the overlapped area is a summation of the weighted Gaussian distributions.

The final stage of the analysis is creating a file that is a visual representation of the deployment area. This file clearly shows the locations of the radiation sources. Google SketchUp ${ }^{\mathrm{TM}}$ (website: http://sketchup.google.com/) is a visualization tool that can be used to quickly and easily create rooms and buildings. A room is created with the same dimensions as the deployment volume and key features such as tables or large objects can be included. Google SketchUp ${ }^{\mathrm{TM}}$ has a 2D import function which allows images or photographs to be placed within the room that has been created. This function is used to paste each wall that was exported from the RTS into the representation of the deployment area. Images can be layered so it is very useful to add any photographs from the deployment area to create a more 
realistic and useful representation of the deployment area and the radiation sources within the deployment area.

\section{SRNL's back-projected radiation analyzer and cell evaluator $\left(\mathrm{BRACE}^{\mathrm{TM}}\right)$}

For a generic radiation characterizer (e.g., RadBall ${ }^{\mathrm{TM}}$ ), using a detector material instead of an electronic detector, a method of reconstructing a contamination profile of the characterized environment is not a trivial task, particularly for complex area sources or nearly even contamination. Detector materials which provide, for example, optical data as output are typically examined by a human, similar to how an x-ray image of a patient is examined by a physician. The human examining the output must make the decisions as to where there is radiation exposure to the material and determine the direction of the source from the optical scan data. Although this method is viable for simple point sources, assuming the number of point sources is limited, it is desirable to produce an automated method of extracting contamination location, energy, and intensity from the data provided by an exposed detector material. A detector material is any material which provides a differential output based on exposure to radiation. This differential output could be changes in OD color, temperature, or the changes could be in electron shell configurations, chemical composition, or some other physical or chemical alteration based on radiation exposure.

The methodology presented in $\mathrm{BRACE}^{\mathrm{TM}}$ is an automated method of extracting source location, energy, and intensity from a collimated exposed detector material. The methodology will work for nearly any detector material which can be read or scanned into a computer data file, providing a $3 \mathrm{D}$ or $2 \mathrm{D}$ matrix of exposure values as integers or floating point numbers. The BRACE ${ }^{\mathrm{TM}}$ methodology required input data, processing steps, and resulting output data are listed below:

Input: Shape, size, and collimation characteristics of the exposed material, as well as the physical layout of the exposed material if more than one is employed; radio-characteristics of the exposed material to extract dose and energy response from the material; location and orientation of the characterizer in the contaminated room; and dimensions of the characterized room and any large objects which could have surface contamination.

Processing steps: For each wall and/or object in the room, BRACE ${ }^{\mathrm{TM}}$ loops through all X, Y points on the surface of the wall or object and provides to the user an image or projection of the contamination locations, intensities, and energies.

Output: Series of 2D images of the intensities at each X, Y point on the walls/objects; series of $2 \mathrm{D}$ images of the energies at each $\mathrm{X}$, Y point on the walls/objects; and a text file with a specific format that describes how to draw 2D line drawings of the contaminated areas on the walls, ceiling, and floor.

The only human interaction required by $\mathrm{BRACE}^{\mathrm{TM}}$ is the input data. In addition, much of the input data will remain constant for each characterization, specifically the data on the characterizer device. The algorithm removes the human from the in-depth processing, which 
reduces error and eliminates the "human opinion" that will vary from one analyst to another, providing consistent and reproducible results.

\subsection{RESULTS AND DISCUSSION}

WESF Cells 6 and 7 were selected to test the RadBall ${ }^{\mathrm{TM}}$ technology because these cells are considered to provide the highest dose rates among the WESF cells. Cells 6 and 7 have similar dimensions $(1.35 \mathrm{~m}$ x $6.63 \mathrm{~m} \times 5.94 \mathrm{~m})$ and same water level $(3.96 \mathrm{~m}$ from the cell bottom) (Figure 7). The WESF cell water temperature oscillates throughout the year, but during the tests it was $20^{\circ} \mathrm{C}$. Four RadBall ${ }^{\mathrm{TM}}$ deployments, summarized in Table 3, were completed at WESF (N-52-1 and N-52-2 in Cell 7 and N-52-3 and N-52-4 in Cell 6). Before deploying RadBall ${ }^{\mathrm{TM}}$, dose rate measurements were obtained in the cells using Elberline RO7 high- and mid-range detectors (http://www.eberlineservices.com) to determine the optimal location for the deployments. N-52-1 and N-52-2 were deployed in the center of Cell 7 at different depths. N-52-3 and N-52-4 deployments in Cell 6 are illustrated in Figure 7. Since the cells were relatively large, two deployments per cell were necessary for a full cell characterization.

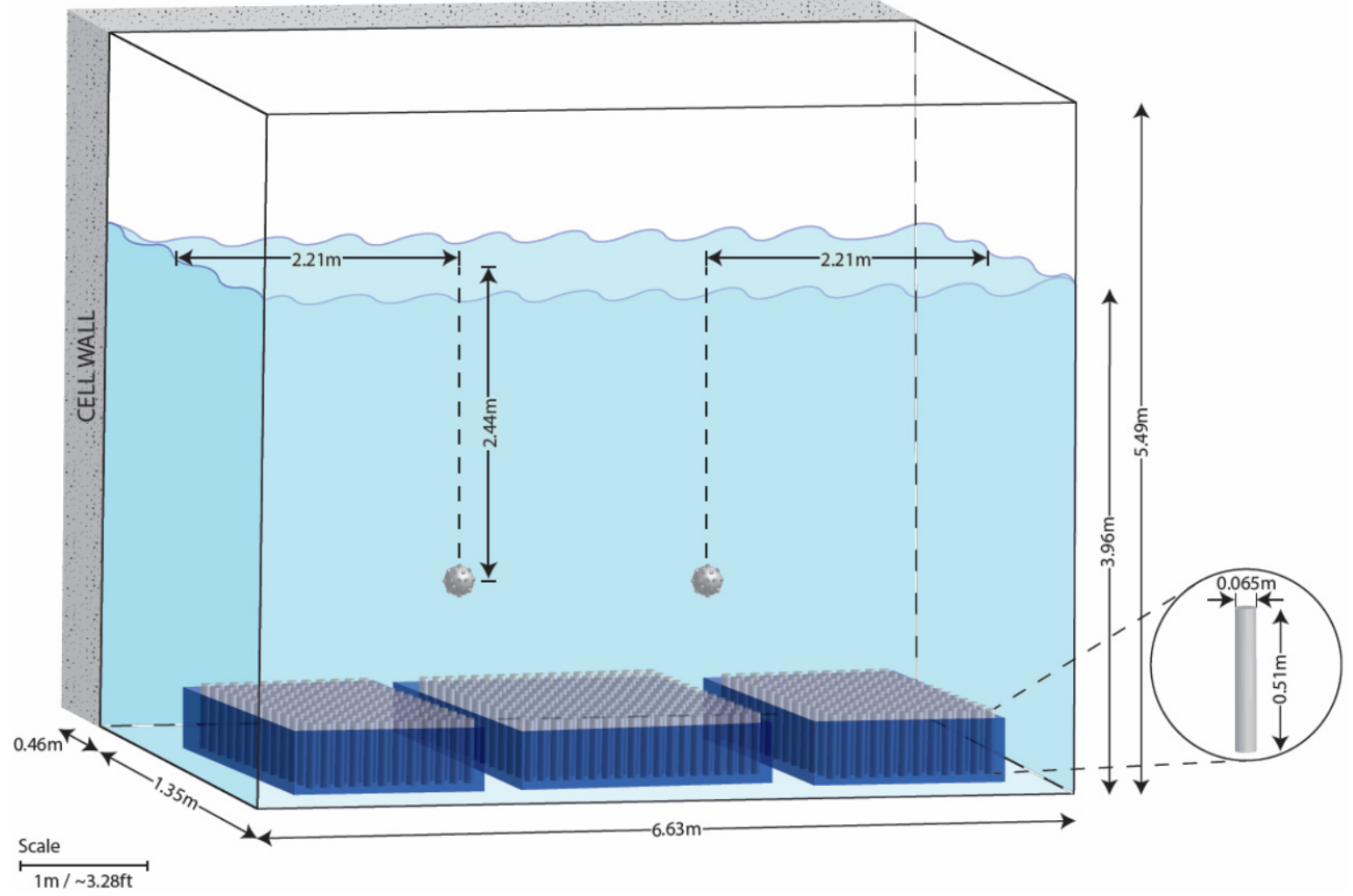

Figure 7 - Representation of the N-52-3 and N-52-4 RadBall ${ }^{\mathrm{TM}}$ deployments in Cell 6.

Three of the four deployments were useful and it was possible to extract data from these irradiated polymers. The preliminary dose rate measurements, obtained for the second deployment (N-52-2), were inaccurate due to a malfunction of the detector, which indicated a dose rate of $0.49 \mathrm{~Gy} \mathrm{hr}^{-1}\left(50 \mathrm{R} \mathrm{hr}^{-1}\right)$. In actuality, the dose rate was much greater (126.10 Gy $\mathrm{hr}^{-1}$ or $13,000 \mathrm{R} \mathrm{hr}^{-1}$ ); therefore, over-irradiation of the PRESAGE ${ }^{\mathrm{TM}}$ polymer occurred, resulting in a total dose of 2,290 Gy $(236,166 \mathrm{R})$. 
Table 3 - RadBall ${ }^{\mathrm{TM}}$ deployments in Hanford Site WESF Cells 6 and 7.

\begin{tabular}{|c|c|c|c|c|c|c|c|}
\hline $\begin{array}{l}\text { RadBall }^{\mathrm{TM}} \\
\text { Deployment }^{2}\end{array}$ & $\begin{array}{c}\text { WESF } \\
\text { Cell } \\
\end{array}$ & $\begin{array}{l}\text { RadBall }^{\mathrm{TM}} \text { distance } \\
\text { from cell bottom }(\mathrm{m})\end{array}$ & $\begin{array}{c}\text { Location } \\
\text { within Cell }\end{array}$ & $\begin{array}{l}\text { Eberline RO-7 } \\
\text { Detector Range }\end{array}$ & $\begin{array}{l}\text { Dose Rate } \\
\left(G_{y ~ h}^{-1}\right)^{a}\end{array}$ & $\begin{array}{l}\text { Deployment } \\
\text { Time (min) } \\
\end{array}$ & $\begin{array}{c}\text { Total Dose } \\
(G y)^{a}\end{array}$ \\
\hline $\mathrm{N}-52-1$ & 7 & 1.37 & Center & High & 9.70 & 83 & 13.42 \\
\hline $\mathrm{N}-52-2^{\mathrm{b}}$ & 7 & 1.14 & Center & Mid & 126.10 & 1,090 & $2,290.82$ \\
\hline $\mathrm{N}-52-3$ & 6 & 1.52 & $\begin{array}{l}2.21 \mathrm{~m} \text { from } \\
\text { east end }\end{array}$ & High & 3.69 & 130 & 7.99 \\
\hline $\mathrm{N}-52-4$ & 6 & 1.52 & $\begin{array}{c}4.42 \mathrm{~m} \text { from } \\
\text { east end }\end{array}$ & High & 3.98 & 114 & 8.62 \\
\hline
\end{tabular}

${ }^{\mathrm{a}}$ The RadBall ${ }^{\mathrm{TM}}$ PRESAGE ${ }^{\mathrm{TM}}$ polymer has equivalent human tissue properties (e.g., density); therefore, the following relationship was used: $1 \mathrm{R}=0.0097$ Gy.

b The detector malfunctioned. Its reading was $0.49 \mathrm{~Gy} \mathrm{~h}^{-1}\left(50 \mathrm{R} \mathrm{h}^{-1}\right)$, but the actual dose rate was $126.10 \mathrm{~Gy} \mathrm{~h}^{-1}\left(13,000 \mathrm{R} \mathrm{h}^{-1}\right)$.

${ }^{c}$ Eberline RO-7 detector website: http://www.eberlineservices.com 
The only physical changes noticeable in N-52-2 were a strange odor and discoloration of the foam used to secure the PRESAGE ${ }^{\mathrm{TM}}$ polymer inside RadBall ${ }^{\mathrm{TM}}$. The polymer was assumed to be uniformly irradiated without any visible tracks. This was later confirmed during the scanning of the polymer using DMOS. The pre-irradiated and over-irradiated (N-52-2) PRESAGE $^{\mathrm{TM}}$ polymer is shown in Figure 8.
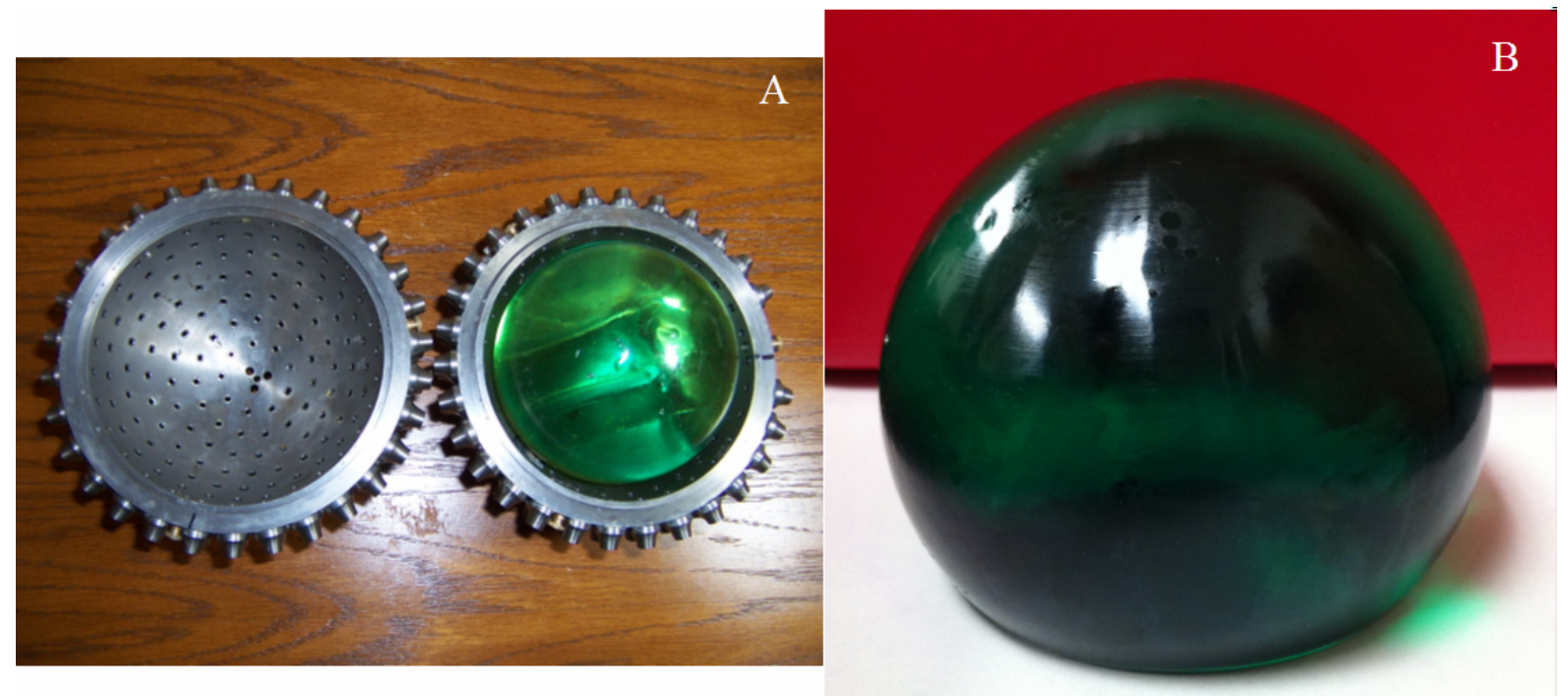

Figure 8 - The (A) pre-irradiated and (B) over-irradiated (N-52-2) PRESAGE ${ }^{\mathrm{TM}}$ polymer.

The deployments at WESF were unique because the RadBall ${ }^{\mathrm{TM}}$ technology has never been used to characterize underwater contaminated areas. The mean free path (MFP) of a 0.662$\mathrm{MeV}{ }^{137} \mathrm{Cs}$ photon in air is $107.34 \mathrm{~m}$ (Table 4). On the other hand, the MFP for the same photon in water is only $0.12 \mathrm{~m}$. Consequently, a photon would have several more collisions in water before it is able to reach the RadBall ${ }^{\mathrm{TM}}$ PRESAGE $^{\mathrm{TM}}$ polymer (Table 5). Due to these collisions, the photons reaching the polymer most likely have a different energy (lower than $0.662 \mathrm{MeV}$ ) and a change of the original photon direction is expected. The distance between the closest ${ }^{137} \mathrm{CsCl}$ capsule and RadBall ${ }^{\mathrm{TM}}$ in Cell 6 was about $0.85 \mathrm{~m}$ with an average number of photon interactions equal to 7.4 (Table 5). RadBall ${ }^{\mathrm{TM}}$ is able to characterize a spherical volume with a maximum radius of $1.16 \mathrm{~m}$, which is equivalent to 10 MFPs for $0.662-\mathrm{Mev}{ }^{137} \mathrm{Cs}$ photons in water. This spherical volume of water is illustrated in Figure 9. Since the WESF capsules are located on the cell floors, the actual RadBall ${ }^{\mathrm{TM}}$ field of view has a conical shape for the WESF cells (Figure 9). The different colors of the four concentric cones in Figure 9 represent various intensities identified by $\operatorname{RadBall}^{\mathrm{TM}}$ (e.g., white represents the highest intensity, red: second highest, etc.). This color representation is also used by BRACE ${ }^{\mathrm{TM}}$ when presenting the results from a cell characterization.

Table 4 - Mass attenuation coefficient and photon mean free path in air and water.

\begin{tabular}{lrr}
\hline Medium $^{\mathrm{a}}$ & $\mu / \rho\left(\mathbf{g ~ c m}^{-2}\right)$ & Mean Free Path $\mathbf{( c m})$ \\
\hline Air & 0.0774 & $10,734.04$ \\
Water & 0.0861 & 11.59 \\
\hline${ }^{\mathrm{a}}$ Air and water temperature at $20^{\circ} \mathrm{C}$.
\end{tabular}


Table 5 - Average number of photon interactions per distance in air and water.

\begin{tabular}{rrr}
\hline \multirow{2}{*}{$\begin{array}{c}\text { Distance } \\
\text { (cm) }\end{array}$} & \multicolumn{2}{c}{ Medium $^{\mathbf{a}}$} \\
\cline { 2 - 3 } & Air & Water \\
\hline 10.00 & 0.00 & 0.86 \\
$\mathbf{1 1 . 5 9}$ & $\mathbf{0 . 0 0}$ & $\mathbf{1 . 0 0}$ \\
20.00 & 0.00 & 1.73 \\
30.00 & 0.00 & 2.59 \\
40.00 & 0.00 & 3.45 \\
50.00 & 0.00 & 4.32 \\
60.00 & 0.01 & 5.18 \\
70.00 & 0.01 & 6.04 \\
80.00 & 0.01 & 6.90 \\
$\mathbf{8 5 . 7 6}$ & $\mathbf{0 . 0 1}$ & $\mathbf{7 . 4 0}$ \\
90.00 & 0.01 & 7.77 \\
100.00 & 0.01 & 8.63 \\
110.00 & 0.01 & 9.49 \\
$\mathbf{1 1 5 . 8 7}$ & $\mathbf{0 . 0 1}$ & $\mathbf{1 0 . 0 0}$ \\
120.00 & 0.01 & 10.36 \\
130.00 & 0.01 & 11.22 \\
140.00 & 0.01 & 12.08 \\
150.00 & 0.01 & 12.95 \\
200.00 & 0.02 & 17.26 \\
300.00 & 0.03 & 25.89 \\
400.00 & 0.04 & 34.52 \\
500.00 & 0.05 & 43.15 \\
$1,000.00$ & 0.09 & 86.30 \\
$5,000.00$ & 0.47 & 431.51 \\
$10,734.00$ & 1.00 & 926.37 \\
\hline${ }^{a}$ Air and water temperature at $20^{\circ} \mathrm{C}$.
\end{tabular}

In addition, characterization of submerged contaminated areas using RadBall ${ }^{\mathrm{TM}}$ presents a complication since the photons that reach the RadBall ${ }^{\mathrm{TM}}$ polymer might come from all the directions (not only from the direction of the sources); thus, generating a semi-uniform irradiation of the polymer. The semi-homogenous OD changes throughout the polymer do not allow for a visual inspection or determination of the radiation tracks in the polymer (no tracks were observed using ImageJ). This lack of visible tracks in the four polymers, illustrated in Figure 10, is attributed to the very high background present in the polymers, complicated by the presence of Schlieren bands, which result from slight PRESAGE ${ }^{\mathrm{TM}}$ polymer in-homogeneities in refractive index as a result of imperfect mixing of the polymer components. These slight refractive index mismatches cause the light to shift out of the acceptance window of the telecentric imaging lens; thus, making them appear very bright in the reconstruction using DMOS. 


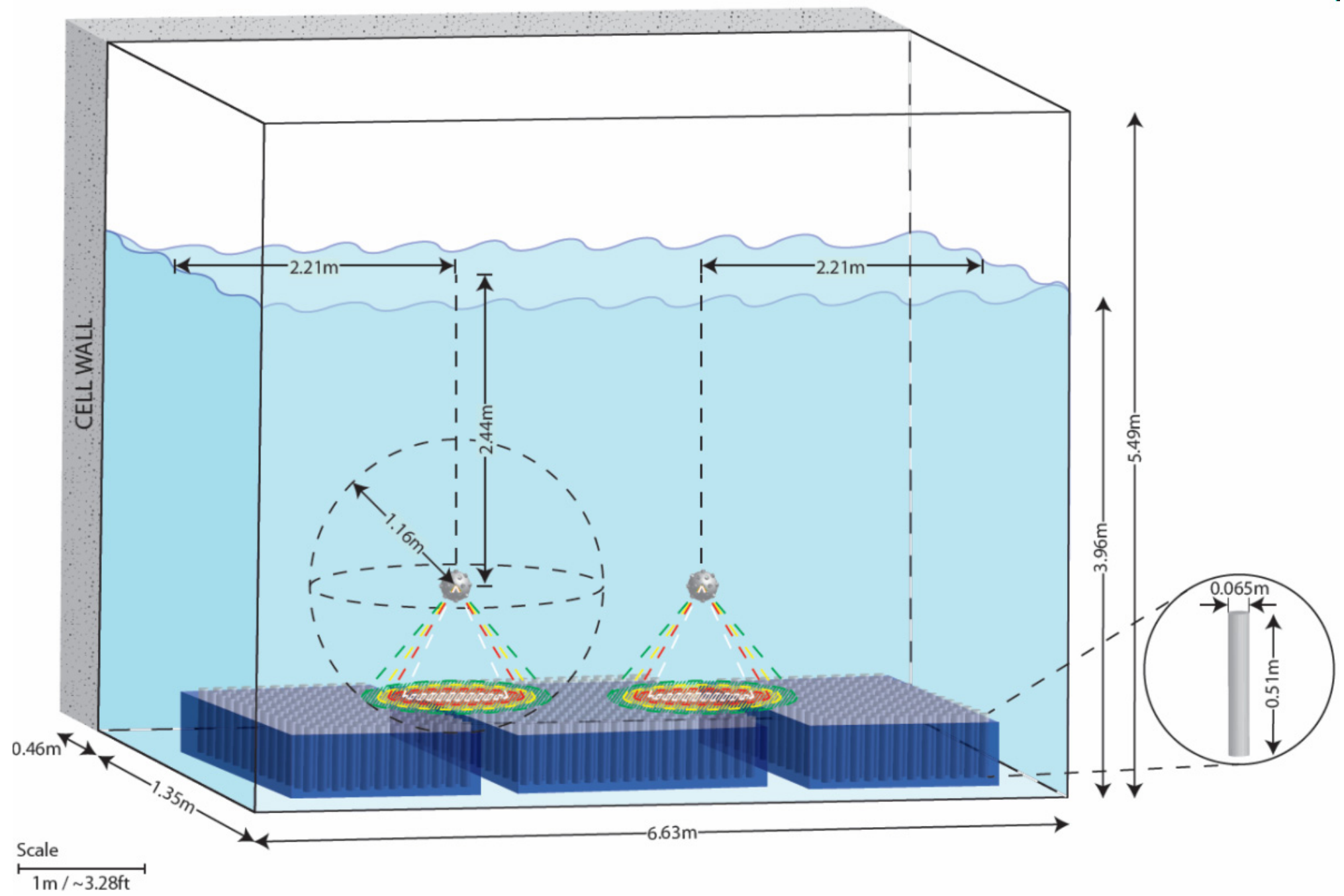

Figure 9 - Representation of the RadBall ${ }^{\mathrm{TM}}$ characterization capabilities in water given by the spherical volume. The different colors of the four concentric cones represent various intensities identified by RadBall ${ }^{\mathrm{TM}}$ (e.g., white represents the highest intensity, red: second highest, etc.). 


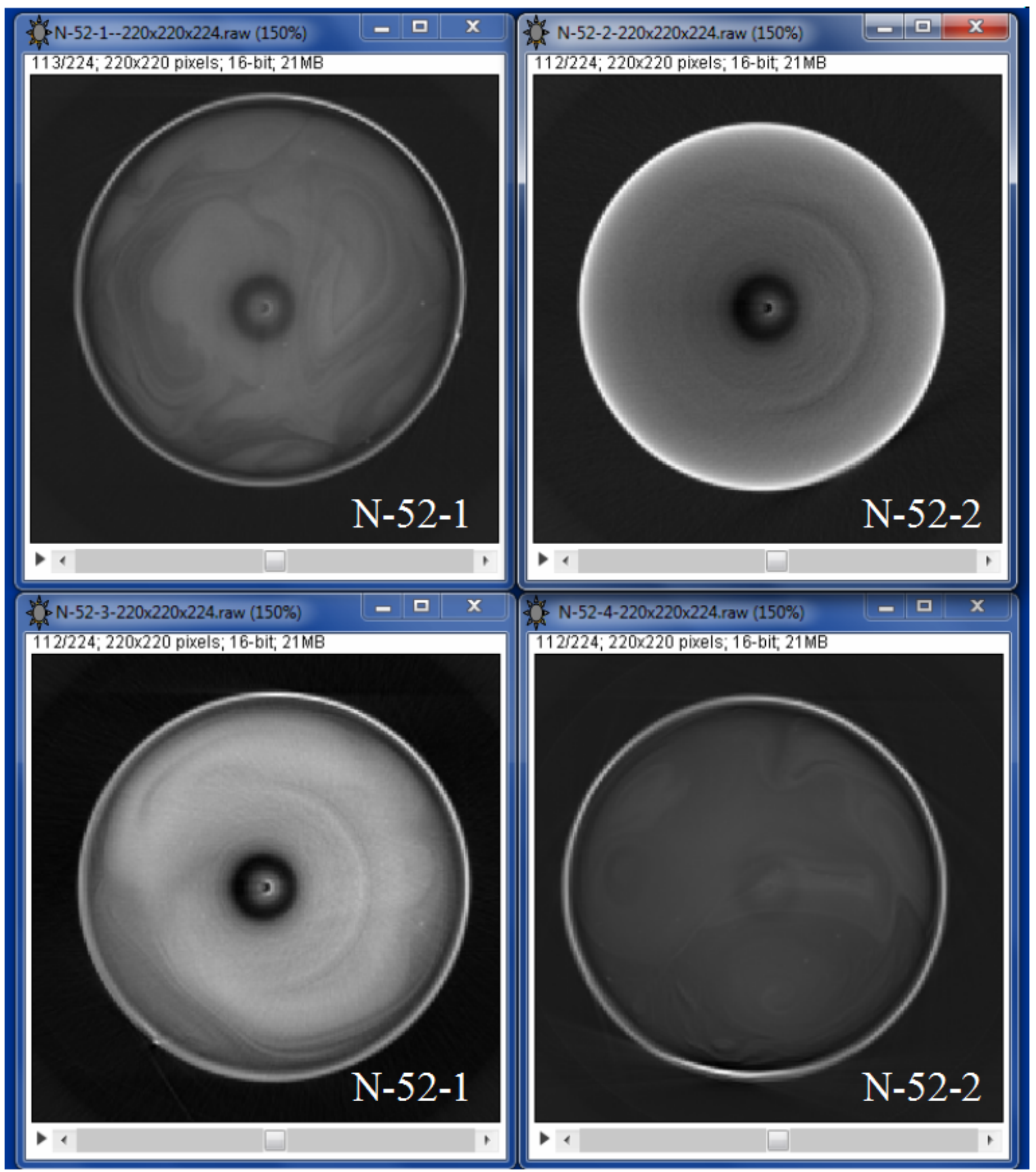

Figure 10 - 2D ImageJ images of the irradiated PRESAGE ${ }^{\mathrm{TM}}$ polymers at WESF.

A central ring artifact was also observed in the polymer and was caused by DMOS inability to distinguish accurate values in the polymer center. Consequently, a sophisticated computer program must be used to detect minimal differences in OD in adjacent polymer regions. $\mathrm{BRACE}^{\mathrm{TM}}$ was used in this study to analyze the DMOS-scan data and generate the cell characterization. 


\section{WESF Cell 6 Characterization}

N-52-3. The N-52-3 RadBall $^{\mathrm{TM}}$ characterization of WESF Cell 6 is presented in Figure 11, which is a side view of the cell, facing south. The capsules on the left contain ${ }^{90} \mathrm{SrF}_{2}$ and produce low energy x-rays from Bremsstrahlung. These low energy photons are very quickly attenuated through water and are invisible to $\mathrm{RadBall}{ }^{\mathrm{TM}}$. The ${ }^{137} \mathrm{CsCl}$ capsules, located directly under and to the right of RadBall ${ }^{\mathrm{TM}}$, produce $0.662 \mathrm{MeV}$ gamma rays that are much more penetrating in water. However, even at this higher energy, these photons have undergone seven or more interactions before reaching RadBall ${ }^{\mathrm{TM}}$ (Table 4 and Table 5); thus, producing a clouded, somewhat uniform, exposure. Nonetheless, RadBall ${ }^{\mathrm{TM}}$ was able to detect the $0.662 \mathrm{MeV}$ gamma rays directly beneath and to its west.

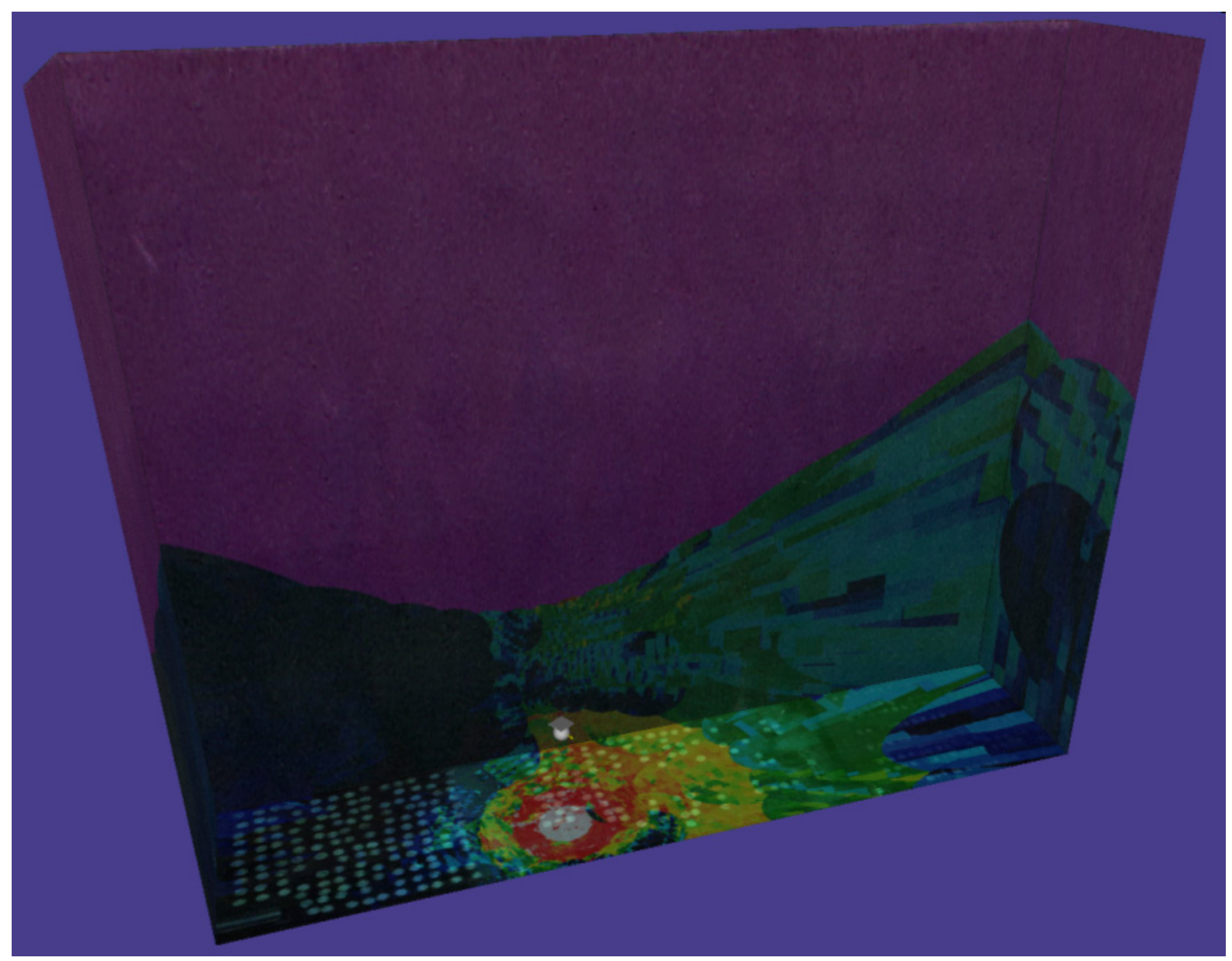

Figure 11 - RadBall ${ }^{\mathrm{TM}}$ Characterization of Cell 6 (N-52-3): Side view, facing south.

BRACE $^{\mathrm{TM}}$ calculates the activity of the more distant submerged capsules as lower since it does not account for the abrupt water attenuation over distance, indicated in Figure 11 by the yellow, green, and blue transition as distance increases. This is because the BRACE ${ }^{\mathrm{TM}}$ algorithm was written to neglect attenuation through the open medium of the cell, typically air. The MFP of $0.662 \mathrm{MeV}$ gamma rays in air is $107.34 \mathrm{~m}$ (Table 4) and the typical hot cells and glove boxes are not larger than $3 \mathrm{~m}$ by $3 \mathrm{~m}$; therefore, neglecting attenuation in air as 
distance increases is a valid assumption for $\mathrm{BRACE}^{\mathrm{TM}}$. With water, however, this attenuation is not negligible due to the relatively small MFP $(0.12 \mathrm{~m})$ of $0.662 \mathrm{MeV}$ gamma rays in water (Table 4). The BRACE ${ }^{\mathrm{TM}}$ algorithm would need to be modified to take distance to a surface into consideration for underwater RadBall ${ }^{\mathrm{TM}}$ deployments. A view down Cell 6, looking west, is illustrated in Figure 12A. The top view of Cell 6, facing down, is shown in Figure 12B. It is evident, as expected, that the ${ }^{90} \mathrm{SrF}_{2}$ capsules did not produce any significant dose to RadBall ${ }^{\mathrm{TM}}$. Figure 13 shows the Cherenkov radiation (blue glow generated from beta particles traveling at ultraphotonic speed) in Cells 6 and 7, Figure 13A and Figure 13B, respectively.

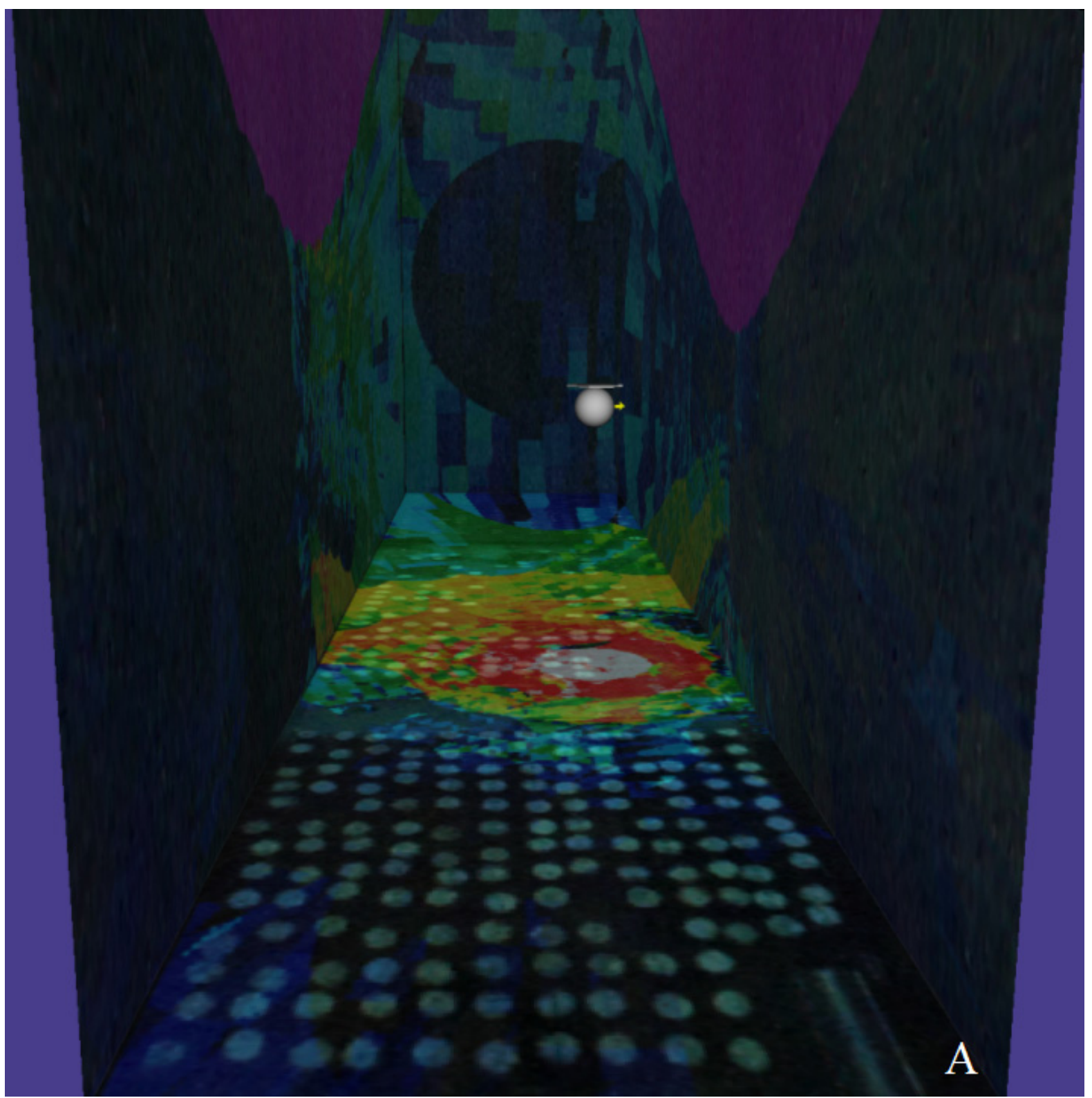

Figure 12 - RadBall $^{\mathrm{TM}}$ Characterization of Cell 6 (N-52-3). A) View down looking west. B) Top view facing south. 


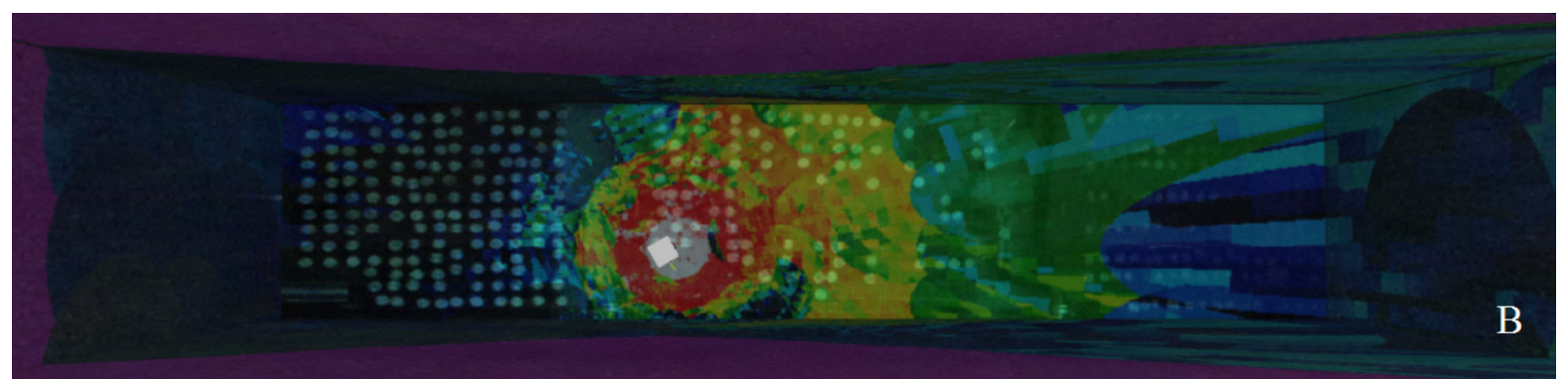

Figure 12 Cont. - RadBall ${ }^{\mathrm{TM}}$ Characterization of Cell 6 (N-52-3). A) View down looking west. B) Top view facing south.
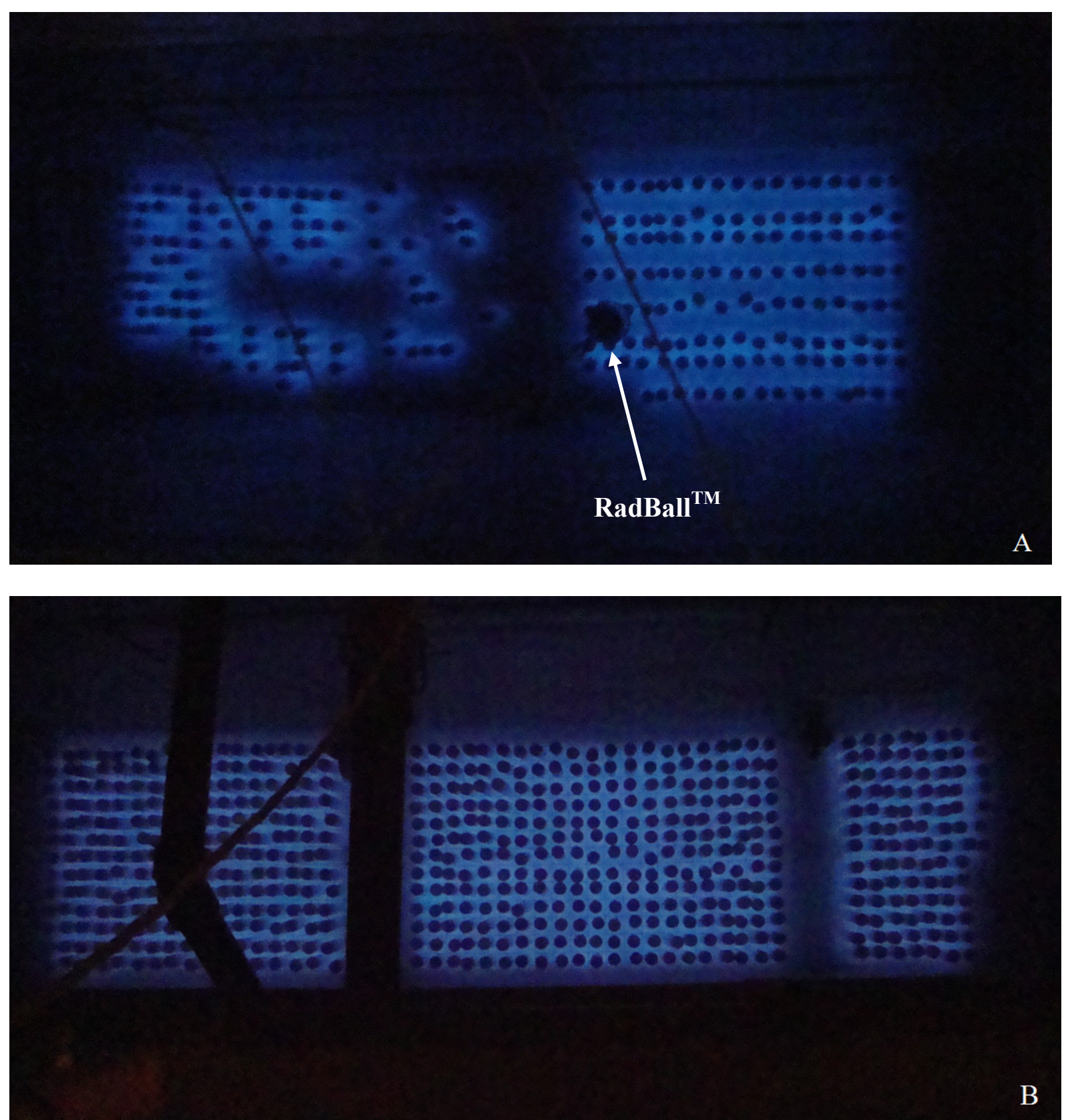

Figure 13 - Cherenkov radiation glow: A) Cell 6. B) Cell 7. 
Figure 14A and Figure 14B (top view of Cell 6, facing south) are overlay images of the $\mathrm{BRACE}^{\mathrm{TM}}$ cell characterization and Cherenkov radiation. It is important to note that ${ }^{90} \mathrm{Sr}$ should give a much brighter blue glow than ${ }^{137} \mathrm{Cs}$, for identical activities. From the photo, the ${ }^{90} \mathrm{Sr}$ capsules are barely glowing indicating a much lower activity compared to the ${ }^{137} \mathrm{Cs}$ capsules.
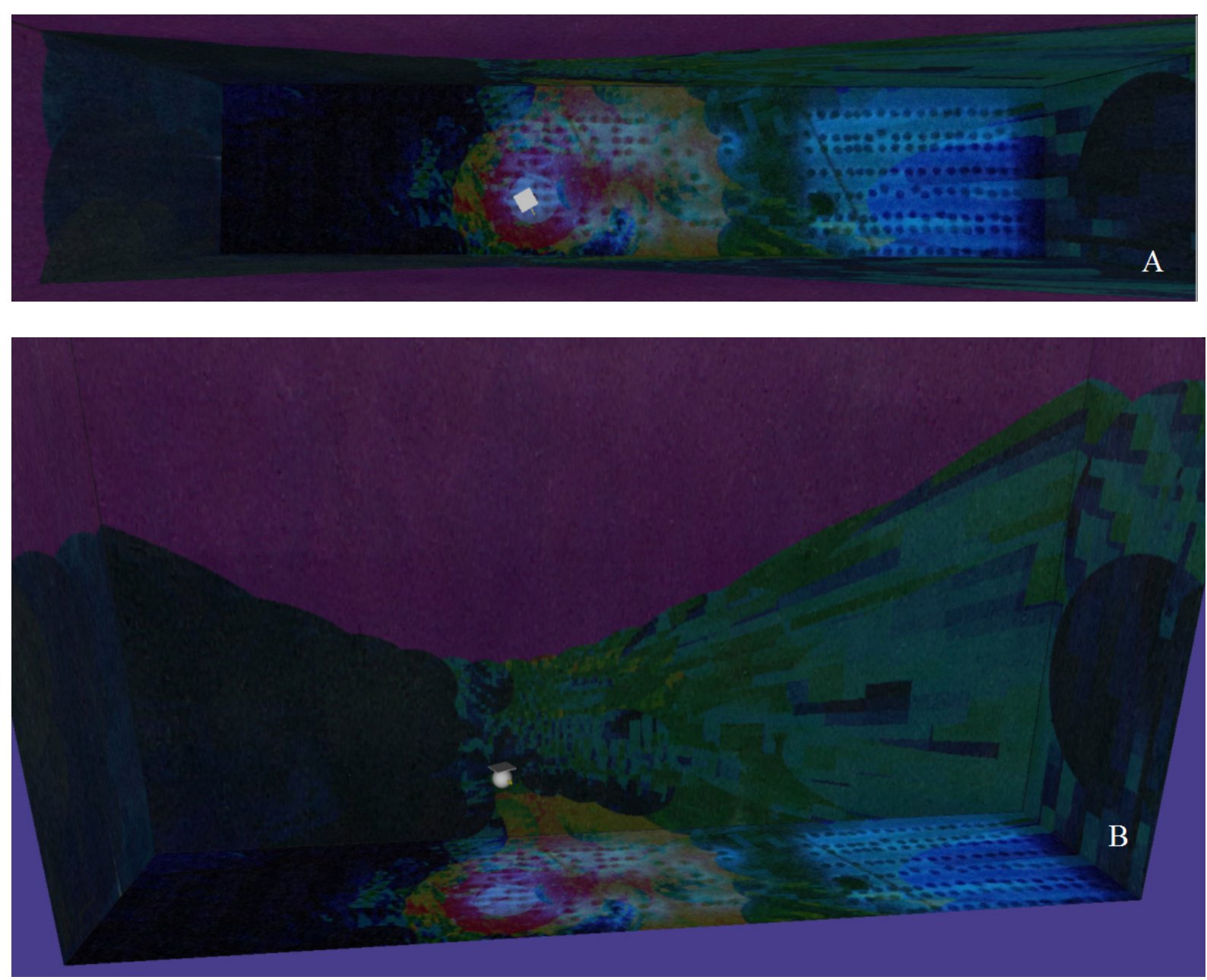

Figure 14 - Overlay of RadBall ${ }^{\mathrm{TM}}$ Characterization of Cell 6 (N-52-3) and Cherenkov radiation glow. A) Top view facing south. B) Side view facing south.

N-52-4. The N-52-4 RadBall ${ }^{\mathrm{TM}}$ characterization of WESF Cell 6 is presented in Figure 15, which is a side view of the cell, facing south. A view down Cell 6, looking west, and top view of Cell 6, facing south, are illustrated in Figure 16A and Figure 16B, respectively. The deployment location is directly over the last 2 or 3 columns of capsules in the west end of the cell. RadBall ${ }^{\mathrm{TM}}$ was essentially uniformly exposed, with an increased exposure directly underneath. The blue areas right outside of the red ring is likely due to the presence of Schlieren bands in the PRESAGE ${ }^{\mathrm{TM}}$ polymer. The overlay images of the BRACE ${ }^{\mathrm{TM}}$ characterization and Cherenkov radiation (top view and side view of Cell 6, facing south) are presented in Figure 17A and Figure 17B. The ${ }^{90} \mathrm{Sr}$ capsules are barely glowing signifying a 
much lower activity compared to the ${ }^{137} \mathrm{Cs}$ capsules. The combined results from both WESF Cell 6 characterizations (N-52-3 and N-52-4) are presented in Figure 18.

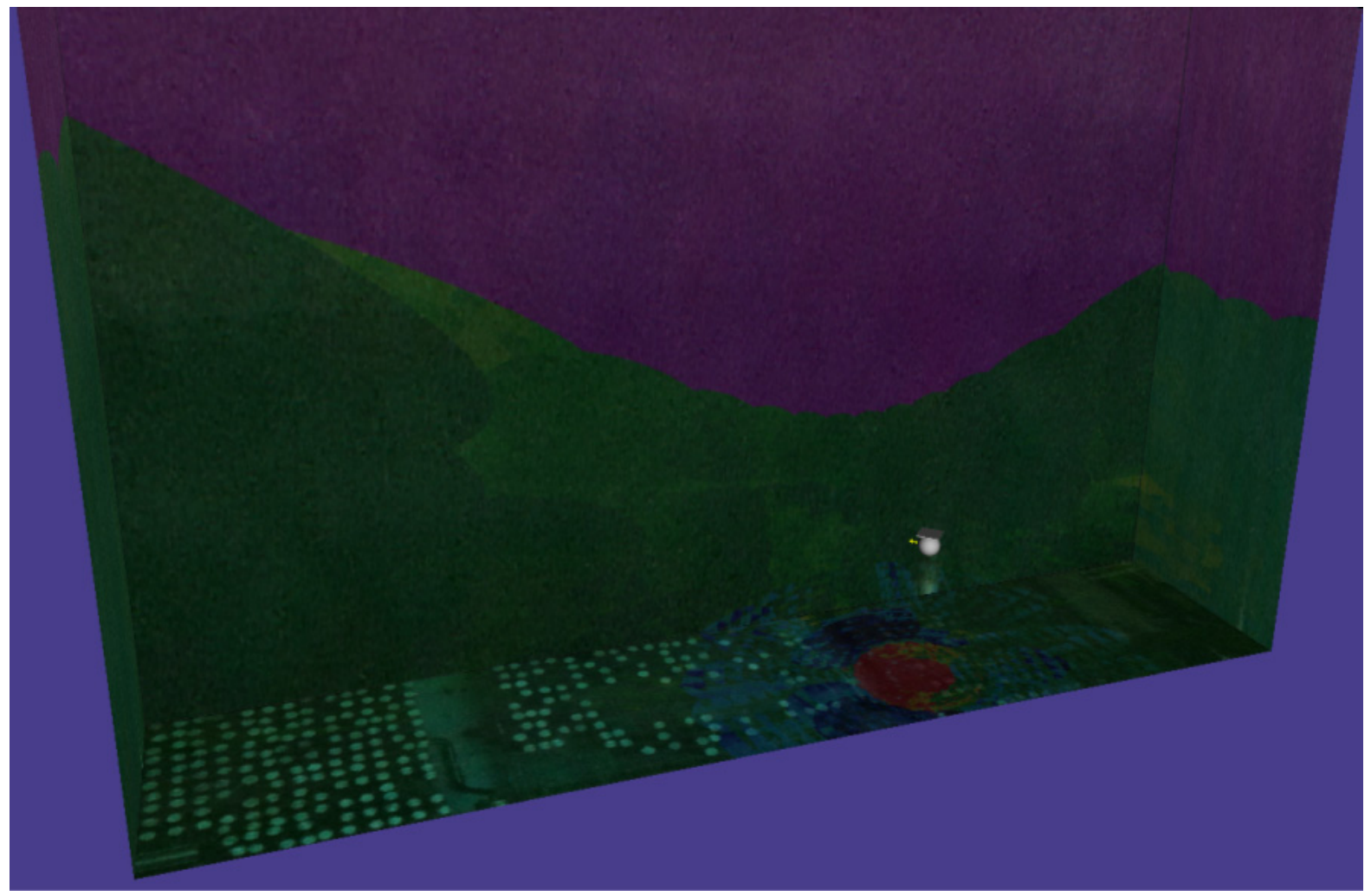

Figure 15 - RadBall ${ }^{\mathrm{TM}}$ Characterization of Cell 6 (N-52-4): Side view, facing south. 

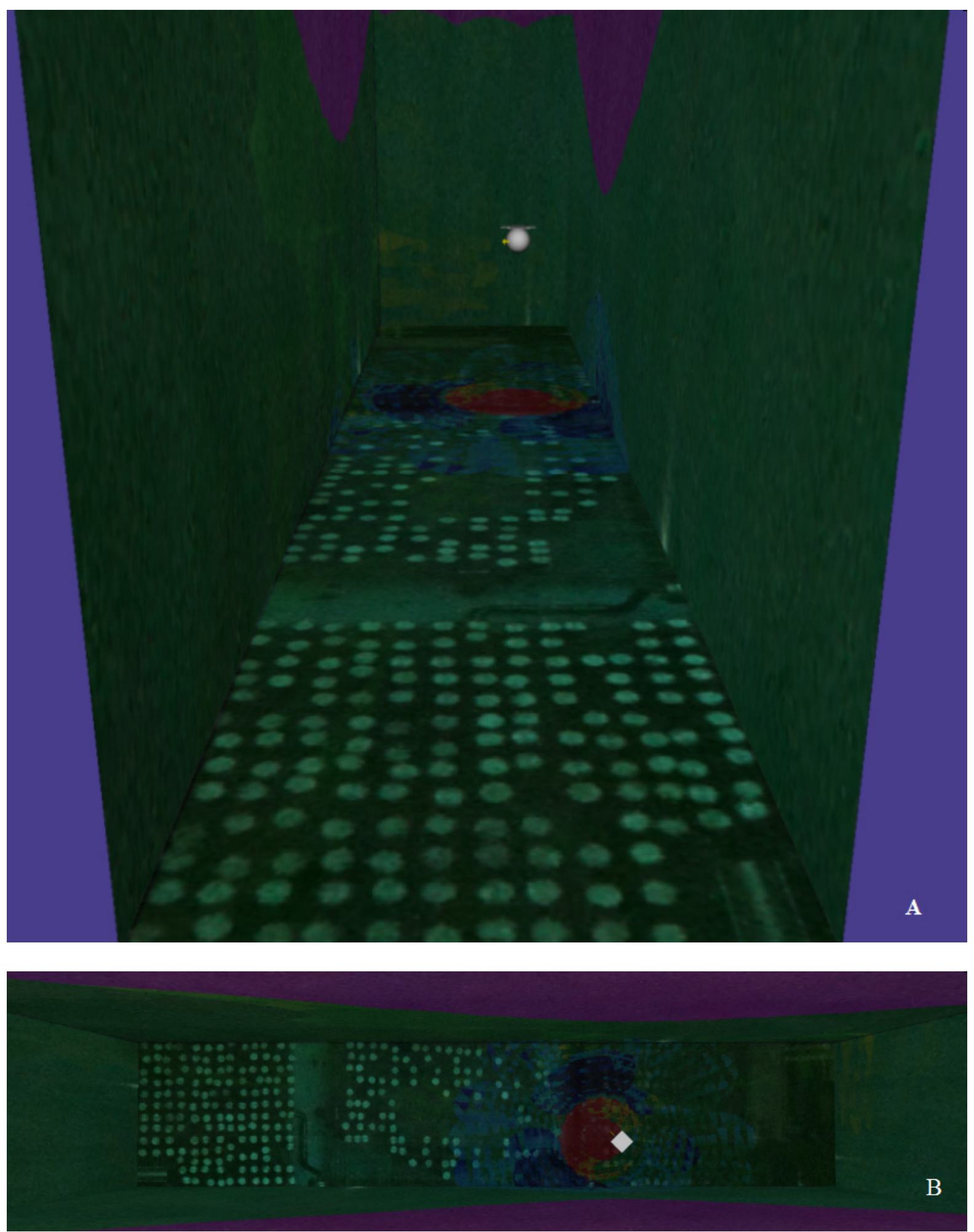

Figure 16 - RadBall ${ }^{\mathrm{TM}}$ Characterization of Cell 6 (N-52-4). A) View down looking west. B) Top view facing south. 

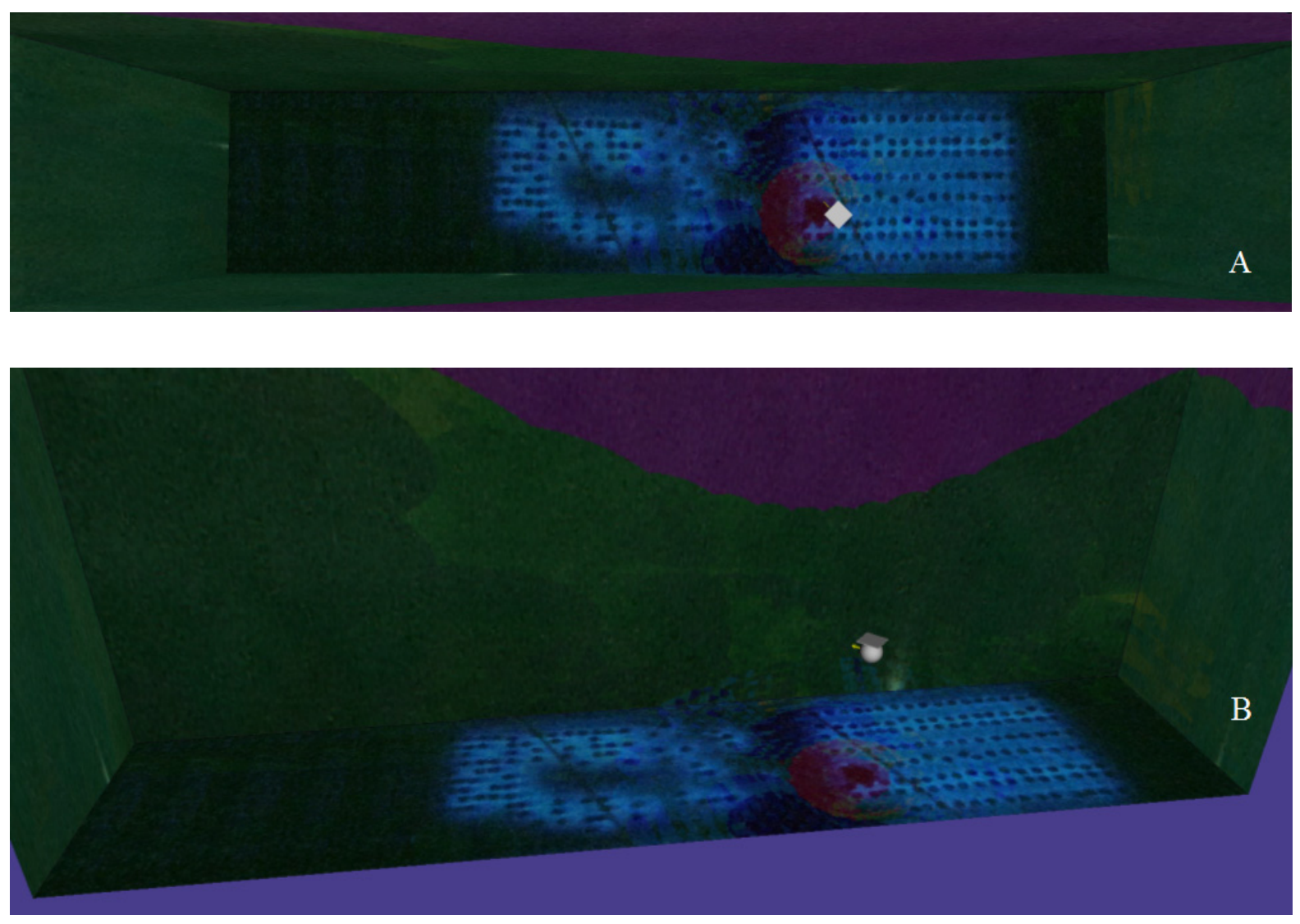

Figure 17 - Overlay of RadBall ${ }^{\mathrm{TM}}$ Characterization of Cell 6 (N-52-4) and Cherenkov radiation glow. A) Top view facing south. B) Side view facing south.

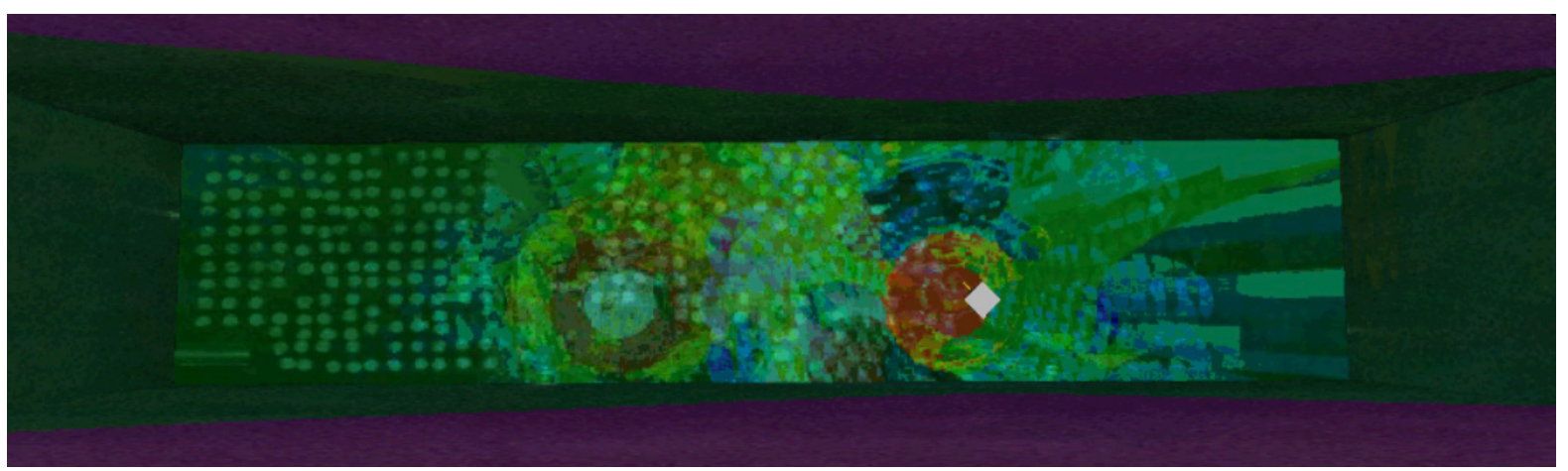

Figure 18 - Combined results from both WESF Cell 6 characterizations (N-52-3 and N-524).

\section{WESF Cell 7 Characterization}

N-52-1. The N-52-1 RadBall ${ }^{\mathrm{TM}}$ characterization of WESF Cell 7 is presented in Figure 19A (side view facing south). All but 2 of the capsules in Cell 7 contain ${ }^{137} \mathrm{Cs}$. There are two ${ }^{90} \mathrm{Sr}$ capsules in the far southeast corner of the cell. The middle and right racks are completely full, with the left rack (containing the two ${ }^{90} \mathrm{Sr}$ capsules) only half full. Although RadBall ${ }^{\mathrm{TM}}$ 
was almost evenly exposed, except for the increased exposure from directly beneath, it was able to determine that there was less overall exposure coming from the rack that is half full (left side). A view of Cell 7, looking west, is shown in Figure 19B. The far wall and floor of the cell indicates a rather uniform exposure. A view down Cell 7 (looking east) and a top view (facing south) are presented in Figure 19C and Figure 19D, respectively. The far wall and floor of this view indicates that RadBall ${ }^{\mathrm{TM}}$ is seeing decreased exposure coming from the rack that is only half full. The overlay images of the $\mathrm{BRACE}^{\mathrm{TM}}$ characterization and Cherenkov radiation (top view and side view of Cell 6, facing south) are presented in Figure 20A and Figure 20B.
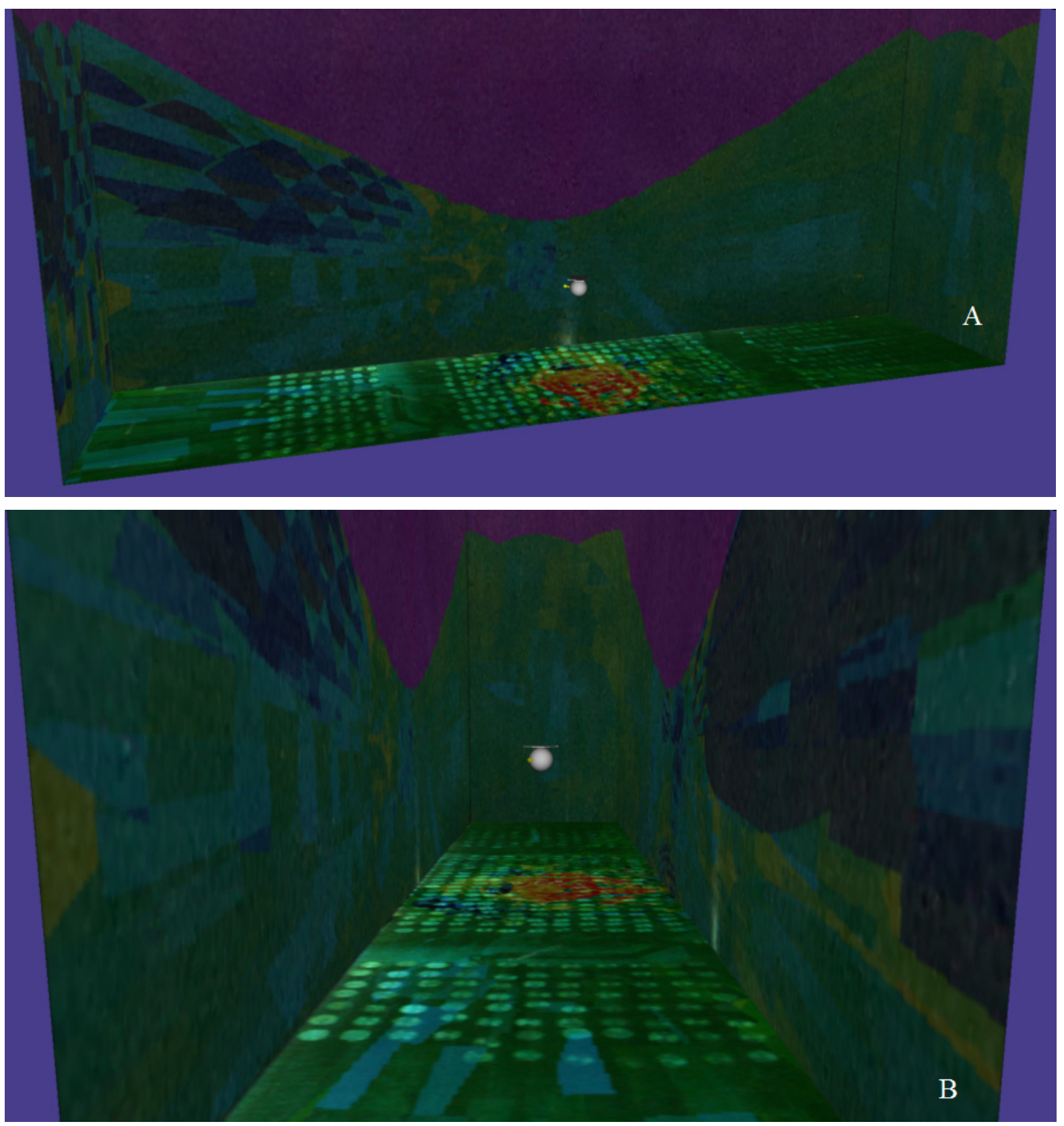

Figure 19 - N-52-1 RadBall ${ }^{\mathrm{TM}}$ characterization of WESF Cell 7: A) Side view facing south. B) View down looking west. C) View down looking east. D) Top view facing south. 

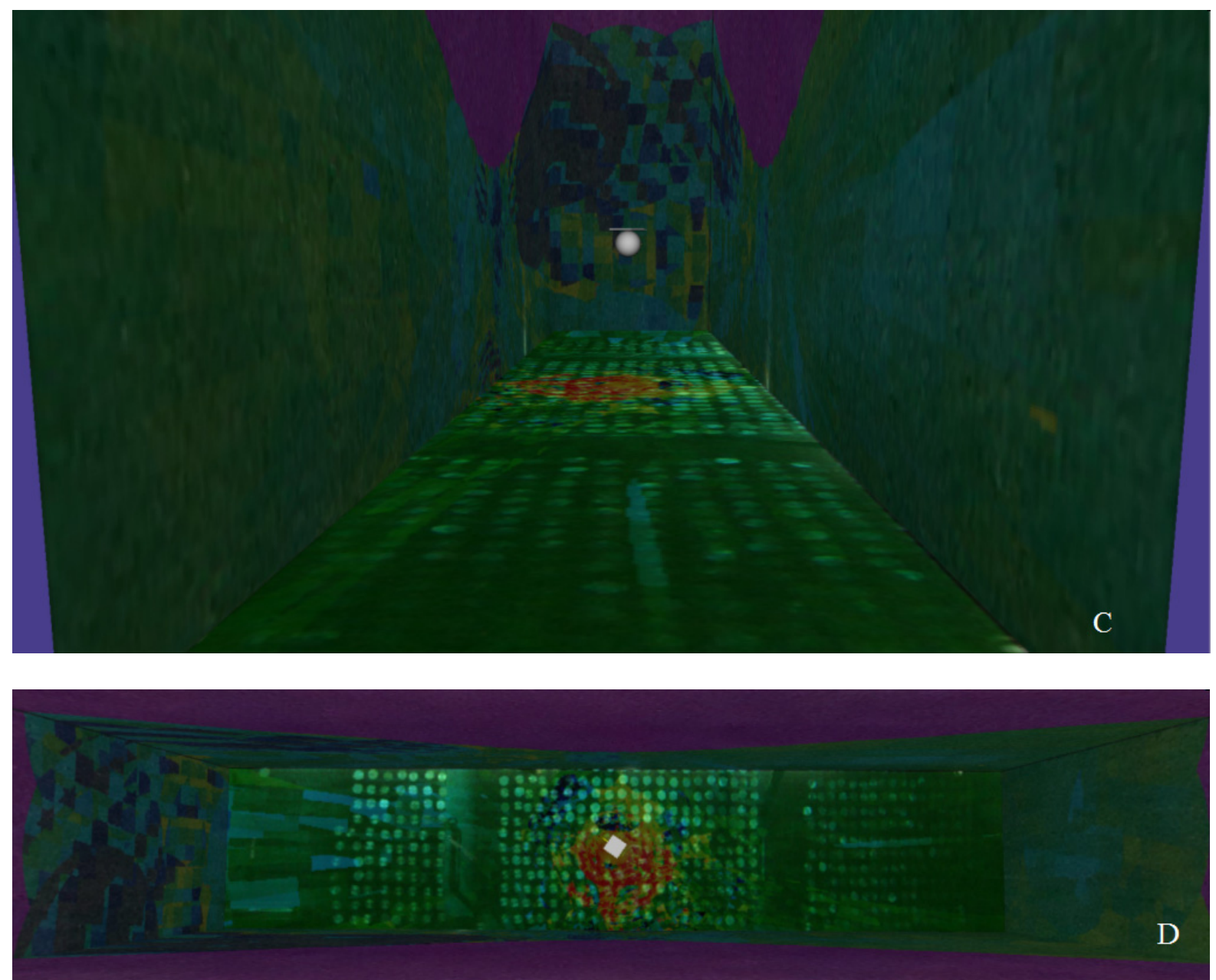

Figure 19 Cont. - N-52-1 RadBall ${ }^{\mathrm{TM}}$ characterization of WESF Cell 7: A) Side view facing south. B) View down looking west. C) View down looking east. D) Top view facing south.

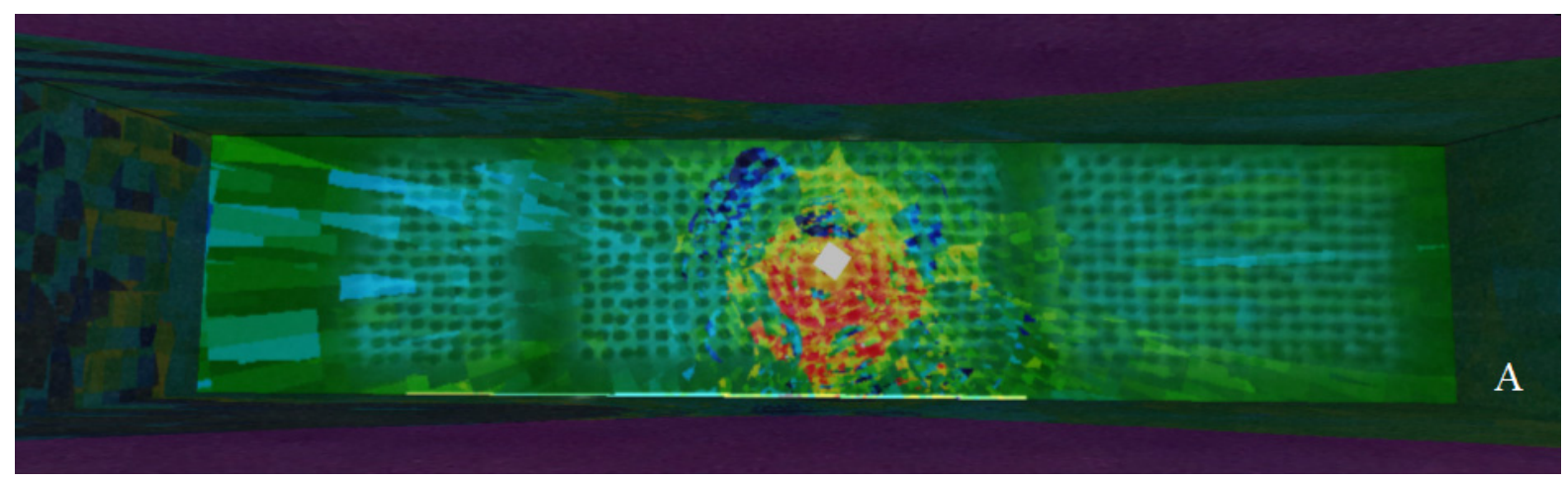

Figure 20 - The overlay images of the $\mathrm{BRACE}^{\mathrm{TM}}$ characterization and Cherenkov radiation: A) Top view and B) side view of Cell 6 , facing south. 


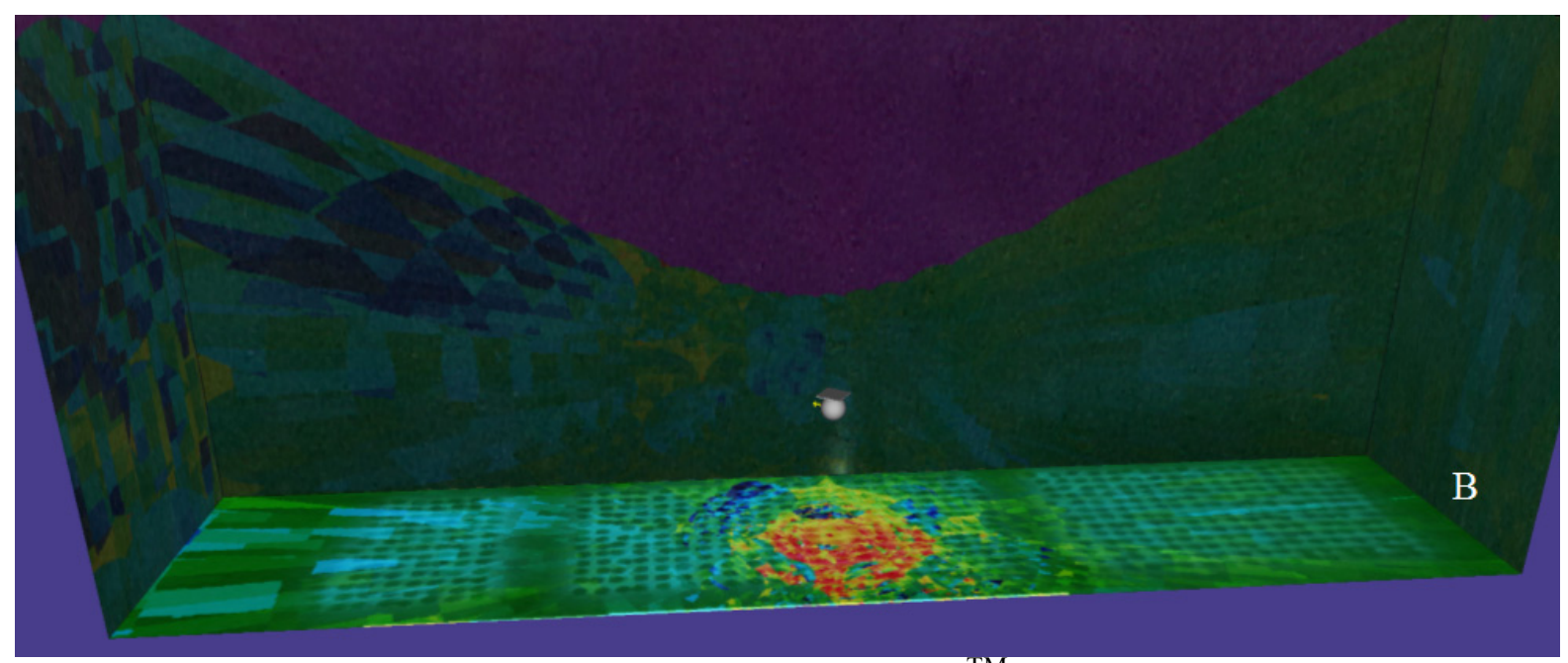

Figure 20 Cont. - The overlay images of the BRACE ${ }^{\mathrm{TM}}$ characterization and Cherenkov radiation: A) Top view and B) side view of Cell 6, facing south.

\section{Monte Carlo modeling}

To better illustrate the effects of water on the scattering of the gammas rays emitted by the capsules, two models were produced for the General Monte Carlo N-Particle Transport Code (MCNP) - Version $5^{1}$ (Figure 21A and Figure 21B). MCNP is a popular Monte Carlo based radiation transport code. Both models depict a void sphere with the same radius as RadBall ${ }^{\mathrm{TM}}$ placed into a chamber with a single point source of $0.662 \mathrm{MeV}$ at $0.86 \mathrm{~m}$ directly beneath the sphere. This is the same distance from the top of the capsules as the deployments at WESF. In one model, the chamber is flooded with dry air (Figure 21A), the other model with water (Figure 21B). A mesh tally was placed over the void RadBall ${ }^{\mathrm{TM}}$ region and the results plotted into an image.
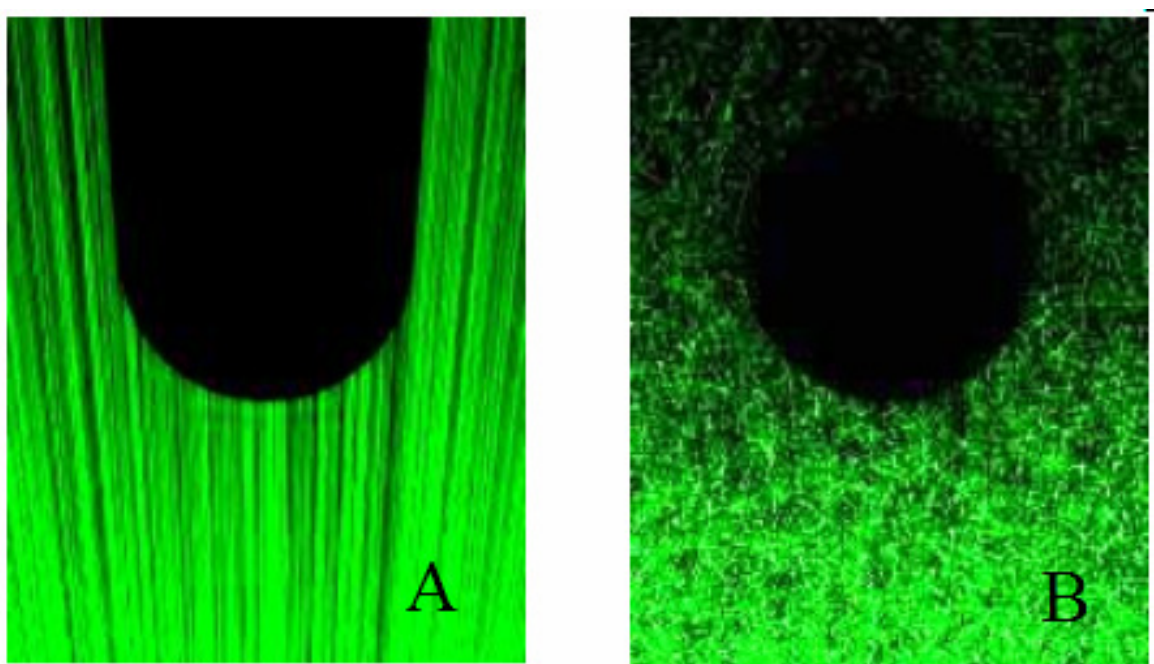

Figure 21 - MCNP modeling in air (A) and water (B).

\footnotetext{
${ }^{1} \mathrm{MCNP}$ is described in great detail at http://mcnp-green.lanl.gov/index.html and is available at http://wwwrsicc.ornl.gov/
} 
For the dry air model, RadBall ${ }^{\mathrm{TM}}$ is exposed with almost completely unscattered photons that are emanating directly from the point source below. Notice that RadBall is exposed only on one side and the photon tracks are essentially linear (Figure 21A). A large shadow is cast above the RadBall ${ }^{\mathrm{TM}}$, as there are almost no interactions, which result in minimal scattering to this region. Much like a flashlight shone into clean water, there is very little to disperse the photons off their linear path.

For the water model (Figure 21B), it is apparent that the photons are no longer linear in direction and tend to scatter randomly because of the relatively short mean free path of the $0.662 \mathrm{MeV}$ photons in water. Due to the tremendous amount of scattering, there are photons impinging RadBall ${ }^{\mathrm{TM}}$ on all sides and from every direction, though not evenly. There is no longer a shadow cast by RadBall ${ }^{\mathrm{TM}}$; however, it is obvious that the bottom is exposed much more than the top. To extend the flashlight example above, this scenario is analogous to shining a flashlight into cloudy water, producing not a narrow beam but a localized flood around the light source dissipating quickly with distance.

These two models are for a single point source, directly beneath the RadBall. The problem is further exacerbated by the many sources located in the WESF pool basin. Because of this flooding effect of the photons, RadBall ${ }^{\mathrm{TM}}$ was only able to capture the difference in exposure levels given to particular sides, and was not able to detect linear photon tracks.

\subsection{CONCLUSIONS}

Previous RadBall ${ }^{\mathrm{TM}}$ tests at NNL, SRNL, and ORNL involved dry deployments where the medium between the radiation sources and RadBall ${ }^{\mathrm{TM}}$ was air. This study involved the investigation of the RadBall ${ }^{\mathrm{TM}}$ technology in four submerged deployments at the Hanford Site's Waste Encapsulation Storage Facility. These underwater deployments presented unique challenges, some of which are: preventing RadBall ${ }^{\mathrm{TM}}$ from becoming contaminated in water filled cells; knowing the position and orientation of RadBall ${ }^{\mathrm{TM}}$ within the cells; determining the correct dose rate and deployment time; extracting information from the almost uniformly irradiated polymers (e.g., no visible radiation tracks) using sophisticated software; accounting for water attenuation and large number of photons collisions before these photons reach RadBall ${ }^{\mathrm{TM}}$; and computer modeling to explain the observed results using a Monte Carlo code.

RadBall $^{\mathrm{TM}}$ is able to characterize a contaminated room, hot cell, or glovebox by providing the locations of the radiation sources and hazards, identifying the radionuclides present within the cell, and determining the radiation sources strength (e.g., intensities or dose rates). These parameters have been previously determined for dry deployments; however, only the location of radiation sources and hazards can be precisely determined for an underwater RadBall $^{\mathrm{TM}}$ deployment. Relative intensities could be more accurately inferred by modifying the RadBall ${ }^{\mathrm{TM}}$ software to account for water attenuation. Currently, the RadBall ${ }^{\mathrm{TM}}$ software, $\mathrm{BRACE}^{\mathrm{TM}}$, can provide relative intensities (similar to a heat map) for underwater deployments represented by various colors. For the WESF cells, these intensities are usually presented as concentric cones due to the location of the sources (positioned on the cell floor). Underwater radionuclide discrimination can be achieved by modifying the software and/or 
hardware (e.g., modifying BRACE ${ }^{\mathrm{TM}}$ and the RadBall $^{\mathrm{TM}}$ device).

Depending on the cell size, a few RadBall ${ }^{\mathrm{TM}}$ devices could be deployed to characterize a submerged cell. The cell dimensions and the photon mean free path in water for specific photon energy must be considered when determining the number of RadBall ${ }^{\mathrm{TM}}$ devices to be used simultaneously for the cell characterization. It is possible to use a single RadBall ${ }^{\mathrm{TM}}$ device to characterize a large cell by using it multiple times in sequence. Considering the size of the WESF cells, three deployments per cell would provide more accurate information on the position of the sources.

The RadBall ${ }^{\mathrm{TM}}$ technology, originally designed for dry deployments, has responded well during the submerged deployments at WESF considering the large number of uncertainties associated with this type of deployment. This study represents the first successful underwater deployment of RadBall ${ }^{\mathrm{TM}}$ and a further step in demonstrating NNL's unique radiation mapping device with the ability to be remotely deployed with no electrical supplies into difficult to access areas and locate and quantify radiation hazards. This study was part of ongoing work to investigate whether the RadBall ${ }^{\mathrm{TM}}$ technology is able to characterize more complex radiation environments.

\subsection{ACKNOWLEDGMENTS}

The authors would like to thank Mr. Andrew P. Szilagyi, Director of the Office of Deactivation and Decommissioning (D\&D) and Facility Engineering (EM-44), U.S. Department of Energy - Office of Environmental Management, for his support of the project entitled "Hot Cell Characterization" involving the testing, verification, and development of the RadBall ${ }^{\mathrm{TM}}$ technology. The authors would also like to thank the Hanford Site for allowing the use of its facilities and Kori Escujuri for coordinating the RadBall ${ }^{\mathrm{TM}}$ deployments at WESF. In addition, the authors would like to express their gratitude to Rebecca Butler (SRNS General Counsel) and Eric Frickey (SRNL Technology Transfer) for their support on the new technologies developed during this project and Jason Davis (SRS Business Exec. \& Employee Comm.) and Brent Douglas (SRS Pub. Rel. \& Media Comm.) for helping with the graphical representations of the ${ }^{137} \mathrm{CsCl}$ capsule and WESF (Figs. 3, 7, and 9). This project is being completed at Savannah River National Laboratory in collaboration with the United Kingdom's National Nuclear Laboratory, Duke University Medical Center, and Heuris Pharma LLC.

\subsection{DISCLAIMER}

This report has been co-authored by Savannah River Nuclear Solutions, LLC under Contract No. DE-AC09-08SR22470 with the U.S. Department of Energy. The United States Government retains and the publisher, by accepting this article for publication, acknowledges that the United States Government retains a non-exclusive, paid-up, irrevocable, worldwide license to publish or reproduce the published form of this work, or allow others to do so, for United States Government purposes. Mention of trade names or commercial products does not constitute endorsement or recommendation for use by the authors or their corresponding organizations. 


\subsection{REFERENCES}

Adamovics J and Maryanski M. Characterization of PRESAGE ${ }^{\mathrm{TM}}$ : a new 3-D radiochromic solid polymer dosimeter for ionizing radiation. Rad. Prot. Dosimetry, 120(4): p. 107-112. 2006.

Doran SJ, Stanley SJ, Jenneson PM, Prott E, Adamovics J. RadBall ${ }^{\mathrm{TM}}$ : a new field for 3D dosimetry, DOSGEL: The 5th International Conference on Radiotherapy Gel Dosimetry, University of Heraklion, Crete; 2008.

Farfán EB, Foley TQ, Stanley SJ, Holmes CJ, Mills RW, Knight P, Mackenzie D, Jannik GT, Oldham M, Clift CG, Thomas A, Adamovic J, Gladden JB. Control Testing of the UK's National Nuclear Laboratory's RadBall ${ }^{\mathrm{TM}}$ Technology at Savannah River National Laboratory, Waste Management 2010, Phoenix, Arizona, USA, 2010a.

Farfán EB, Foley TQ, Jannik GT, Harpring LJ, Gordon JR, Blessing R, Coleman JR, Stanley SJ, Holmes CJ, Oldham M, Adamovics J. RadBall ${ }^{\mathrm{TM}}$ Technology Testing in the Savannah River Site's Health Physics Instrument Calibration Laboratory, The $6^{\text {th }}$ International Conference on 3D Radiation Dosimetry, South Carolina, USA. J. Phys.: Conf. Ser. 250 012080; 2010b.

Farfán EB, Foley TQ, Jannik GT, Harpring LJ, Gordon JR, Blessing R, Coleman JR, Holmes CJ, Oldham M, Adamovics J, Stanley SJ. RadBall ${ }^{\mathrm{TM}}$ Technology Testing and Modeling of the tungsten collimator. The 6th International Conference on 3D Radiation Dosimetry, South Carolina, USA. J. Phys.: Conf. Ser. 250 012081; 2010c.

Farfán EB, Stanley SJ, Holmes CJ, Lennox K, Oldham M, Clift C, Thomas A, John Adamovics J. Locating Radiation Hazards and Sources within Contaminated Areas by Implementing a Reverse Ray Tracing Technique in the RadBall ${ }^{\mathrm{TM}}$ Technology. Sub. to Health Phys. 2011.

Guo P, Adamovics J, Oldham M. Simple 3D validation experiments for PRESAGE ${ }^{\mathrm{TM}}$ /optical-CT dosimetry. J. Phys.: Conf. Ser. 56187-190; 2006a.

Guo P, Adamovics J, Oldham M. Quality assurance in 3D dosimetry by optical-CT J. Phys.: Conf. Ser. 56 191-194; $2006 b$.

Guo P, Adamovics J, Oldham M. Investigation of the dosimetric characteristics of PRESAGE $^{\mathrm{TM}}$. J. Phys.: Conf. Ser. 56 207-210; 2006c.

Knights LM. Waste Encapsulation and Storage Facility Operational Safety Analysis Report, ARH-2967; March 1974.

Oldham M. 3D Dosimetry by Optical-CT scanning. J. Phys.: Conf. Ser. 56 58-71; 2006.

Oldham M, Clift C, Thomas A, Farfán EB, Foley TQ, Jannik GT, Adamovics J, Holmes CJ, Stanley SJ. Initial experience Optical-CT scanning of RadBall ${ }^{\mathrm{TM}}$ Dosimeters. The $6^{\text {th }}$ International Conference on 3D Radiation Dosimetry, South Carolina, USA. J. Phys.: Conf. Ser. 250 012079; 2010.

Sakhalkar HS, Adamovic J, Ibbot G, Oldham M. A comprehensive evaluation of the PRESAGE ${ }^{\mathrm{TM}}$ /optical-CT 3D dosimetry system. Medical Phys. Vol. 36, No. 1; 2009.

Stanley SJ. RadBall ${ }^{\mathrm{TM}}$ : A small deployable polymer based radiation mapping device for locating, quantifying and characterizing contamination in a given cell/glovebox/room, Nuclear Future, 4(6), pp 302-308; 2008.

Stanley SJ, Holmes CJ. Some recent technology developments from the UK's National Nuclear Laboratory to enable hazard characterization for nuclear decommissioning applications, Waste Management 2010, Phoenix, Arizona, USA; 2010. 


\section{Characterizing US Hanford Site Waste Encapsulation Storage Facility Cells Using RadBall $^{\mathrm{TM}}$}

\section{DISTRIBUTION}
A.P. Szilagyi,
DOE-EM-44
W.A. Williams,
DOE-EM-44
J.E. Marra,
SRNL 773-A
J.J. Mayer,
SRNL 773-42A
R.J. Abitz,
SRNL 773-42A
G.T. Jannik,
SRNL 773-42A
SRNL Records,
SRNL 773-52A
EDG Records,
SRNL 773-42A
Hanford Site
UK NNL
Duke University
Heuris Pharma, LLC 